\title{
Magnetosphere-ionosphere-thermosphere coupling: Effect of neutral winds on energy transfer and field-aligned current
}

\author{
G. Lu, A. D. Richmond, B. A. Emery, and R. G. Roble \\ High Altitude Observatory, National Center for Atmospheric Research, Boulder, Colorado
}

\begin{abstract}
The assimilative mapping of ionospheric electrodynamics (AMIE) algorithm has been applied to derive the realistic time-dependent large-scale global distributions of the ionospheric convection and particle precipitation during a recent Geospace Environment Modeling (GEM) campaign period: March 28-29, 1992. The AMIE outputs are then used as the inputs of the National Center for Atmospheric Research thermosphere-ionosphere general circulation model to estimate the electrodynamic quantities in the ionosphere and thermosphere. It is found that the magnetospheric electromagnetic energy dissipated in the highlatitude ionosphere is mainly converted into Joule heating, with only a small fraction $(6 \%)$ going to acceleration of thermospheric neutral winds. Our study also reveals that the thermospheric winds can have significant influence on the ionospheric electrodynamics. On the average for these 2 days, the neutral winds have approximately a $28 \%$ negative effect on Joule heating and approximately a $27 \%$ negative effect on field-aligned currents. The field-aligned currents driven by the neutral wind flow in the opposite direction to those driven by the plasma convection. On the average, the global electromagnetic energy input is about 4 times larger than the particle energy input.
\end{abstract}

\section{Introduction}

The high-latitude ionosphere is directly impacted by the interaction between the solar wind and magnetosphere through magnetic coupling. As a result, the high-latitude ionospheric plasma convection configuration depends strongly on the orientation and strength of the interplanetary magnetic field (IMF) [e.g., Heelis, 1984; Potemra et al., 1984; Reiff and Burch, 1985; Lyons, 1985; Sojka et al., 1986; Heppner and Maynard, 1987]. The convecting ions in turn set the neutral gas into motion through ion drag. The neutral wind therefore tends to follow the ion convection [e.g., Hays et al., 1984; Killeen et al., 1984; McCormac et al., 1987]. On the other hand, the ionosphere is not totally passive in the determination of ion and neutral motions. It is now well known that the thermospheric winds can also produce dynamo effects that contribute to the overall electrodynamics of the coupled magnetosphereionosphere-thermosphere system [Blanc and Richmond, 1980; Killeen el al., 1984; Lyons et al., 1985; Richmond and Roble, 1987; Forbes and Harel, 1989; Thayer and Vickrey, 1992; Deng et al., 1993].

The National Center for Atmospheric Research thermosphere-ionosphere general circulation model (NCAR

Copyright 1995 by the American Geophysical Union.

Paper number 95JA00766.

0148-0227/95/95JA-00766 $\$ 05.00$
TIGCM) as well as its older version, the TGCM, have been widely used to investigate the thermospheric features for different periods of geophysical interest [e.g., Killeen and Roble, 1984; Lyons et al., 1985; Roble et al., 1987, 1988a; Forbes et al., 1987; Deng et al., 1991, 1993; Thayer and Vickrey, 1992]. All these studies have invoked empirical magnetospheric inputs of convection and particle precipitation to the models. Crowley et al. [1989] made the first effort to incorporate realistic time-dependent northern hemispheric convection patterns derived from the assimilative mapping of ionospheric electrodynamics (AMIE) procedure into the TGCM in their simulation of the thermospheric response during the equinox transition study (ETS) interval of September 18-19, 1984. However, they adopted the empirical convection model of Heelis et al. [1982] for the southern hemisphere and also made use of the particle precipitation inputs that were based on empirical auroral parameterization of Roble and Ridley [1987]. The focus of their study was thermospheric dynamics, that is, the distributions of the thermospheric temperature, wind, and composition. In this paper, we study the magnetosphere-ionosphere-thermosphere coupling in the high-latitude region. We focus more on the ionospheric/thermospheric electrodynamic features, such as energy dissipation, Joule heating, and field-aligned current. Unlike Crowley et al. [1989], we use both realistic time-dependent ionospheric convection and auroral precipitation patterns derived from the AMIE procedure as the inputs to the upgraded 
TIGCM. The primary difference between the two models is the self-consistent calculation of the ionosphere in the TIGCM [Roble et al., 1988b], whereas the ionosphere is cmpirically specified in the TGCM [Dickinson et al., 1981]. We study the period March 28-29, 1992, a Geospace Environment Modeling (GEM) campaign period for which a set of comprehensive data has been collected from satellites, radars, and ground magnetometers.

This paper is organized as follows. In section 2 we will describe the theoretical approach of this study, the AMIE procedure and the TIGCM model, as well as the data sets used in this study. In section 3 we will present and discuss the high-latitude height-integrated patterns of Joule heating, mechanical power, electromagnetic energy dissipation, and field-aligned current in the northern hemisphere. We will also discuss the comparison of various global energy inputs. Our main findings will be summarized in section 4 .

\section{Procedure}

\subsection{Theoretical Approach}

At high latitudes the electromagnetic interaction between the ionosphere and magnetosphere can be expressed in terms of energy exchange by Poynting's theorem (see, for example, Thayer and Vickrey, 1992):

$$
\frac{\partial w}{\partial t}+\nabla \cdot\left(\frac{\vec{E} \times \vec{B}}{\mu_{0}}\right)+\vec{J} \cdot \vec{E}=0
$$

where $w$ is the electromagnetic energy density, $\vec{E}$ is the electric field, $\vec{B}$ is the magnetic field, $\mu_{0}$ is the magnetic permeability of free space, and $\vec{J}$ is the current density. We work in a reference frame rotating with the Earth, and also ignore the Coulomb force associated space charge density. For a static case, the first term in (1) vanishes so that the electromagnetic energy flux (or Poynting flux) flowing into or out of the surface of a unit volume in the ionosphere is compensated by the energy dissipated (i.e., $\vec{J} \cdot \vec{E}>0$ ) or generated (i.e., $\vec{J} \cdot \vec{E}<0$ ) within the volume. The rate of energy transfer to the medium $\vec{J} \cdot \vec{E}$ is essentially equal to $\vec{J}_{\perp} \cdot \vec{E}$, since the electric field component along $\vec{B}$ is usually much smaller than the perpendicular component in the ionosphere. This quantity can be written as the sum of two terms,

$$
\vec{J}_{\perp} \cdot \vec{E}=\underbrace{\vec{J}_{\perp} \cdot \vec{E}^{\prime}}_{\varepsilon_{J}}+\underbrace{\vec{U} \cdot(\vec{J} \times \vec{B})}_{\varepsilon_{W}}
$$

where $\vec{E}^{\prime}=\vec{E}+\vec{U} \times \vec{B}$ is the electric field in the frame of neutral wind $\vec{U}$. The term $\varepsilon_{J}$ is Joule heating, while $\varepsilon_{W}$ is the rate of work done by the Ampere force $\vec{J} \times \vec{B}$ on the neutral gases. The total Joule heating rate can be further expressed as

$$
\begin{aligned}
\vec{J}_{\perp} \cdot \vec{E}^{\prime} & =\sigma_{P}(\vec{E}+\vec{U} \times \vec{B})^{2} \\
& =\underbrace{\sigma_{P} E^{2}}_{\varepsilon_{0}}+\underbrace{\sigma_{P}|\vec{U} \times \vec{B}|^{2}-2 \sigma_{P} \vec{U} \cdot(\vec{E} \times \vec{B})}_{\varepsilon_{1}}
\end{aligned}
$$

where $\sigma_{P}$ is the Pedersen conductivity. The first term on the right-hand side of (3), i.e., $\varepsilon_{0}$, is what the Joule heating rate would bc in the absence of any wind, and has often been used in the past to give an approximate estimate of Joule heating in the regions where the ion drift velocity $(\vec{E} \times \vec{B}) / B^{2}$ greatly exceeds $\vec{U}$. The sum of the second and third terms, i.e., $\varepsilon_{1}$, simply represents the modification of Joule heating due to the presence of neutral winds, and thus gives a measure of the error in trying to estimate Joule heating by considering only ion convection. For the sake of simplicity in terminology, we call $\varepsilon_{0}$ "convection heating" and $\varepsilon_{1}$ "wind heating." Note that the "wind heating," $\varepsilon_{1}$, depends on both the neutral wind velocity and the electric field (or the ion drift velocity). Since the neutral wind speed is usually smaller than the ion drift speed at high latitudes, the value of the "wind heating" can be negative, if the wind flows in the same direction as the ion drifts. In such cases, the total Joule heating is reduced. It is apparent that the magnetosphere, ionosphere, and thermosphere are intrinsically coupled so that the contributions of the neutral wind dynamo to the total electrodynamic fields cannot be simply separated from that of the magnetospheric dynamo.

Thayer and Vickrey [1992] and Deng et al. [1993] investigated the relative importance of the neutral wind dynamo and the magnetospheric dynamo; they found that the neutral wind dynamo contributes significantly to the ionospheric electrodynamics. In their simulations, however, they treated the magnetospheric dynamo and the neutral wind dynamo as acting independently by using the term, $\varepsilon_{0}=\sigma_{p} E^{2}$, to represent the magnetospheric dynamo and a term, $\varepsilon_{U}=$ $-\sigma_{p}(\vec{U} \times B)^{2}$, to represent the thermospheric wind dynamo. Although such simplification may provide some general information about the two different energy generators, it does not take into account the interrelated nature of the magnetosphere-ionosphere-thermosphere system. To further elucidate this point, (2) can be rewritten explicitly as

$$
\begin{aligned}
\vec{J}_{\perp} \cdot \vec{E} & =\left[\sigma_{P}(\vec{E}+\vec{U} \times \vec{B})+\sigma_{H} \hat{b} \times(\vec{E}+\vec{U} \times \vec{B})\right] \cdot \vec{E} \\
& =\underbrace{\sigma_{P} E^{2}}_{\varepsilon_{0}} \underbrace{-\sigma_{P}(\vec{U} \times \vec{B})^{2}}_{\varepsilon_{U}} \\
& +\underbrace{\sigma_{P} \vec{E} \cdot(\vec{U} \times \vec{B})+\sigma_{H} B(\vec{U} \cdot \vec{E})+\sigma_{P}(\vec{U} \times \vec{B})^{2}}_{\varepsilon_{E U}}
\end{aligned}
$$

where $\hat{b}$ is a unit vector of the magnetic field. The $\varepsilon_{E U}$ value in (4) readily cancels out $\varepsilon_{U}$ and leaves two other terms which depend on both the wind velocity and the electric field. Therefore, the net electromagnetic energy transfer from the magnetosphere to thermosphere, for a coupled magnetosphere-ionosphere-thermosphere system, cannot be wholly represented by the sum of $\varepsilon_{0}$ and $\varepsilon_{U}$, as done in the studies of Thayer and Vickrey [1992] and Deng et al. [1993].

Unlike the analysis of energy transfer, the analysis of electric current does allow ready separation into com- 
ponents associated independently with $\vec{E}$ and $\vec{U}$. The field-aligned current density $j_{\|}$at the top of the ionosphere, defined to be positive, if it flows out of the ionosphere, is found from consideration of current continuity to be

$$
\begin{aligned}
j_{\|}= & -\frac{1}{\sin I} \int_{z_{1}}^{z_{2}} \nabla \cdot\left[\sigma_{P} \vec{E}+\sigma_{H} \hat{b} \times \vec{E}\right] d z \\
& -\frac{1}{\sin I} \int_{z_{1}}^{z_{2}} \nabla \cdot\left[\sigma_{P}(\vec{U} \times \vec{B})+\sigma_{H} \hat{b} \times(\vec{U} \times \vec{B})\right] d z
\end{aligned}
$$

where $I$ is the downward inclination angle of $\vec{B}, z$ is altitude, and $z_{1}$ and $z_{2}$ are the bottom and top of the region of significant Pedersen and Hall conductivity. The first integral term on the right-hand side of (5) is the fieldaligned current density due to the plasma convection, while the second integral represents the field-aligned current due to the neutral wind. Strictly speaking, this integral is meant to be taken along the slanted magnetic field line, but unless there are highly structured features present, a vertical integration provides an adequate approximation. Geometrical spreading of field lines in altitude is also ignored in (5) for simplicity.

\subsection{AMIE}

The AMIE procedure [Richmond and Kamide, 1988; Richmond, 1992] is an optimally constrained, weighted least squares fit of coefficients to the observed data. Each data set is weighted by the inverse square of its effective error so that less reliable data contribute less to the fitting. The AMIE procedure also incorporates a priori empirical information about electric potential and ionospheric conductance to improve the estimates in the region where the data coverage is sparse (see Richmond [1992] for more details).

The following is a brief description of the data that are incorporated into AMIE to derive the global distributions of the ionospheric convection and particle precipitation during the period of March 28-29, 1992.

Satellite measurements. Satellites provide valuable data during this period, including the four Defense Meteorological Satellite Program (DMSP) spacecraft (F8-F11), the NOAA 12 satellite, the Akebono (EXOS D), and the Upper Atmospheric Research Satellite (UARS). The DMSP spacecraft are in Sun-synchronous circular orbits at an altitude about $840 \mathrm{~km}$, with orbital inclination of $98.7^{\circ}$ and orbital period of about 100 min. All four DMSP satellites measure the crosstrack horizontal and vertical ion drift components. In addition, F10 and F11 can also measure the along-track velocity component. However, due to some technical problems in reducing the along-track velocity component, only the cross-track ion drift data are used in the AMIE procedure. The precipitating particles with energies between $32 \mathrm{eV}$ and $30 \mathrm{keV}$ are measured by the DMSP satellites, whereas only those electrons within the restricted energy range from $460 \mathrm{eV}$ to $30 \mathrm{keV}$ are considered in calculating the average energy and energy flux [Rich et al., 1987] that are incorporated into AMIE. The NOAA 12 satellite is also a polar-orbiting satellite, with an altitude of $850 \mathrm{~km}$ and orbital pe- riod of $100 \mathrm{~min}$. The satellite observes the auroral precipitating particles in the energy range from $300 \mathrm{eV}$ to $20 \mathrm{keV}$. EXOS D is in an orbit of inclination $75^{\circ}$ and orbital period $212 \mathrm{~min}$. The apogee and perigee of the satellite are 10,500 and $270 \mathrm{~km}$, respectively. During the March 1992 period, the satellite altitude varied from about 1100 to $8500 \mathrm{~km}$ over the northern polar region. No data were obtained from the satellite when it was passing over the southern hemisphere, because the ground receivers in the southern hemisphere were not operating during that period. EXOS D measures the two-dimensional electric fields, perpendicular to the satellite spin axis. The vector electric field is calculated with the assumption that the electric field along the main magnetic field is zero (see Hayakawa et al. [1990] for further information). UARS is in a near-circular orbit at $585 \mathrm{~km}$, with an inclination of $57^{\circ}$. The onboard atmospheric $\mathrm{X}$ ray imaging spectrometer (AXIS) measures 3 - to $10-\mathrm{keV} \mathrm{X}$ rays that are generated as energetic electrons penetrate the atmosphere [Chenette et al., 1993; Winningham et al., 1993]. The characteristic energy and energy flux of the precipitating electrons can then be extracted from the X-ray spectra [Chenette et al., 1993; Winningham et al., 1993].

Radar observations. The Sondrestrom incoherent scatter radar was operating between 0440 and 2000 UT on March 29, 1992. Ion drift vectors were extracted from the line-of-sight components and averaged every 5 min over $1^{\circ}$ bins between $72^{\circ}$ and $76^{\circ}$ magnetic latitude. Additionally, the Sondrestrom radar measured the ionospheric conductances. During this 2-day period, the Goose Bay HF radar provided vector ion drift velocities which were averaged every $10 \min$ over $2^{\circ}$ bins from $65^{\circ}$ to $81^{\circ}$ magnetic latitude.

Ground magnetometer data. During this campaign period, there were 68 ground magnetometer stations monitoring the magnetic perturbations; among them seven stations were from the southern hemisphere. The magnetic perturbations are used primarily to determine the ionospheric current and electric field but are also used to modify the ionospheric conductance based on the empirical formula of Ahn et al. [1983b]. The average energy and energy flux of the precipitating electrons can then be inverted from the empirical formulas of the height-integrated Pedersen and Hall conductances [Robinson et al., 1987].

Figure 1 shows the northern hemispheric patterns of the ionospheric convection (top), mean electron energy (middle), and precipitating electron energy flux (bottom) derived from AMIE at 1000 UT on March 29. The patterns are based on the data described above, as well as the information from the statistical models of electric potential [Foster et al., 1986] and auroral conductance [Fuller-Rowell and Evans, 1987]. The convection pattern consists of two cells: a round-shaped dusk cell and a crescent-shaped dawn cell. The total cross-polar-cap potential drop is $81 \mathrm{kV}$, given at the upper right. Although there were no IMF data available at this particular time, such a well organized two-cell pattern usually corresponds to an IMF with positive $B_{y}$ and negative $B_{z}$ [e.g., Reiff and Burch, 1985; Heppner and Maynard, 

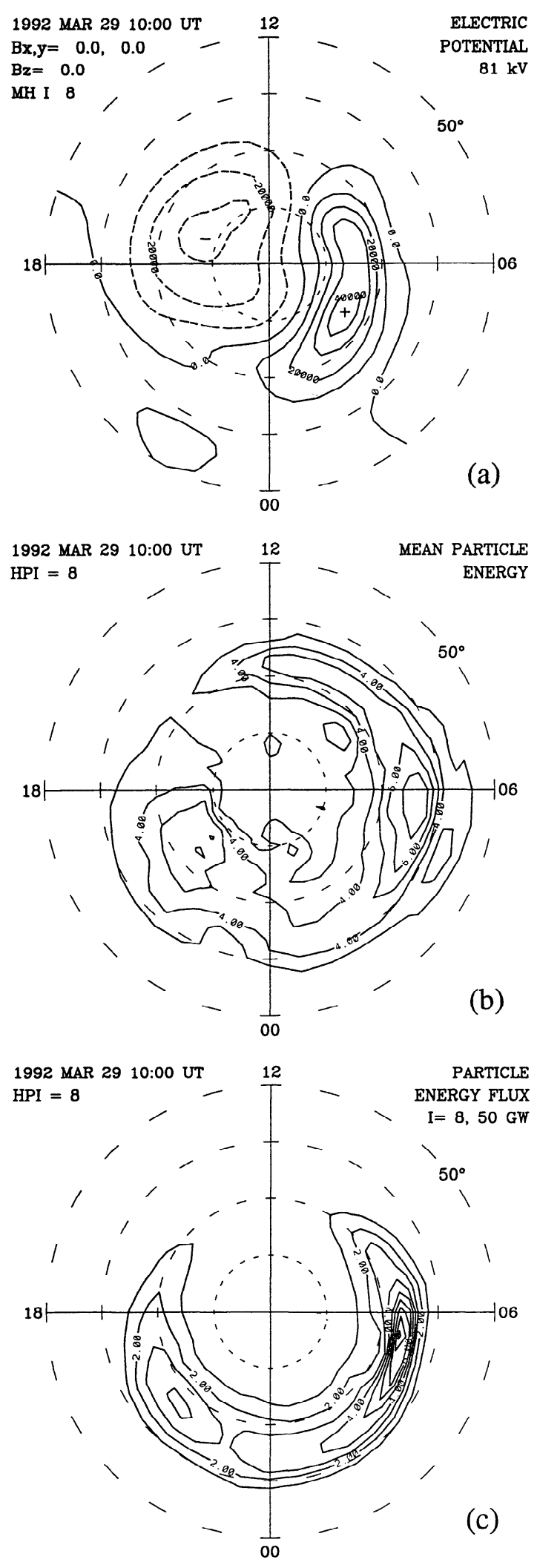

Figure 1. (a) The northern-hemisphere ionospheric convection pattern derived at 1000 UT on March 29, 1992 , plotted in apex magnetic coordinates. The pattern has a contour interval of $10 \mathrm{kV}$, with dashed lines indicating negative potentials and solid lines indicating positive potentials. (b) Distribution of the mean electron energy, with a contour interval of $1 \mathrm{keV}$. (c) Distribution of the precipitating electron energy flux. The contour interval is $1 \mathrm{~mW} / \mathrm{m}^{2}$.
1987]. The electron precipitation is mainly confined to the auroral region, with a mean energy between 3 and 5 $\mathrm{keV}$ and a median energy flux around $3 \mathrm{~mW} / \mathrm{m}^{2}$. The total hemisphere-integrated energy flux from electron precipitation is $50 \mathrm{GW}$.

\subsection{TIGCM}

The NCAR TIGCM model has been developed to calculate a self-consistent thermospheric and ionospheric structure, taking into account the dynamic coupling between the thermospheric neutral wind and the ionospheric plasma [Roble et al., 1988b]. However, no electrodynamic feedback from the thermospheric wind to the magnetospheric electric field is considered in the model. The TIGCM has an effective $5^{\circ}$ latitudelongitude geographic grid with 25 constant pressure levels in the altitude range from approximately 97 to 500 $\mathrm{km}$. The time step can be flexible, varying from 3 to 6 min, depending on the inputs. The external inputs to the TIGCM are the solar EUV and UV fluxes, the auroral particle precipitation, the ionospheric convection, and the semidiurnal tides at the lower boundary.

For the period March 28-29, 1992, the 2-day average solar radiation index $\mathrm{S}_{a}$ is $188.5 \times 10^{-22} \mathrm{~W} / \mathrm{m}^{2} \mathrm{~Hz}$. The time-dependent patterns of the high-latitude ionospheric convection and particle precipitation are derived from AMIE, with 5-min resolution; while the low-latitude and midlatitude ionospheric convection is derived from the empirical model of Richmond et al. [1980]. Because of relatively poor ground data coverage in the southern hemisphere, on a few occasions when there is no satellite passing overhead, the southern hemispheric patterns derived from AMIE become unrealistic. In such cases the convection patterns from the northern hemisphere are adopted but altered in the polar cap to account for the IMF $B_{y}$-induced asymmetry between the two hemispheres, whereas the corresponding northern hemispheric auroral precipitation patterns are used for the southern hemisphere, assuming there is conjugacy. For this reason, we concentrate on the physical interpretation of the northern hemisphere simulations. Although the lower-thermospheric waves generated in the southern hemisphere may propagate into the northern hemisphere [Croulley et, al., 1989], the use of the adjusted northern hemispheric patterns in the southern hemisphere is not expected to significantly affect the northern hemisphere simulations, especially the height-integrated electrodynamic quantities which are the main interest for this study. Before being incorporated into the TIGCM, the AMIE patterns are first converted from magnetic coordinates to geographic coordinates. The semidiurnal tide model as described by $\mathrm{Fe}$ sen et al. [1991] is included at the lower boundary of the TIGCM. The TIGCM is first run to obtain a diurnally reproducible solution. For this background run, the patterns of the ionospheric convection and particle precipitation at 0200 UT on March 28 are chosen as inputs to the TIGCM, which corresponds to a relatively quiet geomagnetic condition. The time-dependent AMIE patterns are then incorporated into the TIGCM for a realistic simulation of the high-latitude thermospheric dy- 
namics. A 3-min time step is used for the entire simulation, and linear interpolations of input values are made at a given time step. The TIGCM histories are recorded hourly for the 2 days that we studied.

\section{Results}

\subsection{Joule Heating}

Previous studies on the global distribution of Joule heating were based on either spatially limited direct radar observations [e.g., Banks et al., 1981; Vickrey et al., 1982; Foster et al., 1983] or indirect measurements, such as those involving magnetogram inversion techniques [Ahn et al., 1983a; Kamide and Kroehl, 1987]. Furthermore, these studies have all excluded the neutral wind effects on the heating owing to the difficulty in obtaining a realistic wind pattern. In the TIGCM model, the thermosphere and ionosphere are calculated self-consistently so that accurate estimations of the neutral wind dynamics can be achieved.

Plate 1 presents the hourly patterns of the heightintegrated "convection heating" (i.e., $\varepsilon_{0}$ in (3)), at 0800 , 0900,1000 , and 1100 UT on March 29, 1992. This was a period of a moderate substorm, and Plates 1a-1d correspond approximately to the pre-substorm phase, the expansion phase, the peak of the expansion phase, and the recovery phase. The patterns are plotted in the northern hemisphere above $42.5^{\circ}$ geographic latitude, with the geographic pole at the center and local solar time shown around the periphery of the dial. The color scale represents the power intensity in units of $\mathrm{mW} / \mathrm{m}^{2}$. Note that the color scale is from 0 to $24 \mathrm{~mW} / \mathrm{m}^{2}$ except for the pattern at $1000 \mathrm{UT}$, in which the color scale is from 0 to $65 \mathrm{~mW} / \mathrm{m}^{2}$. The arrows indicate the ion drift velocities that have been externally imposed on the TIGCM. As illustrated in Plate 1, Joule heating is distributed nonuniformly over the polar region, with some localized hot spots. At $1000 \mathrm{UT}$, the peak of the substorm expansive phase, the heating is most intense (notice the change in the color scale). Plate 1 also shows that the intense heating is mostly found on the dawn and dusk sides of the polar cap, where the higher speed sunward convections are located.

Plate 2 shows the height-integrated "wind heating" (i.e., $\varepsilon_{1}$ in (3)). Note that the color scale now ranges from -9 to $5 \mathrm{~mW} / \mathrm{m}^{2}$, with negative values indicating cooling and positive values indicating heating. The arrows represent the effective neutral winds which have been weighted in altitude by the Pedersen conductivity. The effective winds correspond roughly to the neutral winds at about the $z=-1$ constant pressure surface (around $160 \mathrm{~km}$ altitude). Comparison between Plates 1 and 2 shows an anti-correlation between the convection heating and the wind heating, that is, the winds tend to counteract the convection heating. This occurs in the regions where the convection speed is relatively large so that ion drag becomes locally important.

The high-latitude ionospheric convection is controlled by the solar wind-magnetosphere interaction both at the dayside magnetopause and at the nightside mag- netotail and therefore is highly variable and dependent upon the interplanetary magnetic field orientation [e.g., Cowley et al., 1991, and references therein]. Observations have shown that the response time to changes in the IMF is about $4-5 \mathrm{~min}$ in the dayside ionosphere [Lockwood et al., 1986; Todd et al., 1988; Etemadi et al., 1988], and about $30 \mathrm{~min}$ on the nightside [Baker et al., 1983]. As illustrated in Plate 1, during this 4-hour substorm period, the ion convection varies drastically. The maximum convection speed increases from $750 \mathrm{~m} / \mathrm{s}$ at $0900 \mathrm{UT}$ to $1500 \mathrm{~m} / \mathrm{s}$ at $1000 \mathrm{UT}$, the peak of the substorm, then reduces to $700 \mathrm{~m} / \mathrm{s}$ at $1100 \mathrm{UT}$.

The neutral winds, on the other hand, take a much longer time to respond to changes in ionospheric convection. The time lag between the ion convection and neutral wind is roughly one and a half hours in the $F$ region, and about 3 hours in the $E$ region [Killeen and Roble, 1984; Roble et al., 1987]. Even after the ionospheric convection totally ceases, the neutral winds can persist for several hours [Roble et al., 1987] and drive a significant ionospheric current system [Lyons et al., 1985]. Such wind dynamo effects are referred to as the "flywheel" effect [Banks, 1972]. The effective wind patterns shown in Plate 2 consist of two cells, with an enhanced antisunward flow over the polar cap and sunward flow in the auroral region. The wind patterns, however, do not exactly resemble the two-cell convection patterns. For instance, at $0800 \mathrm{UT}$, there is about a $1 \frac{1}{2}$-hour time lag between the winds and the ion drifts across the polar cap. There is also an apparent spatial asymmetry between the dawn and dusk cells in the neutral wind patterns: a broad dusk cell and a confined dawn cell. This asymmetry is caused by the weak sunward flow in the dawnside auroral region. At lower latitudes, the flow even becomes antisunward. Similar features have been reported previously, and are attributed to the Coriolis force which contributes more favorably to the clockwise circulation on the duskside than it does to the anti-clockwise circulation on the dawnside [Fuller-Rowell and Rees, 1981, 1984; Killeen and Roble, 1984, 1986; Thayer et al., 1987; Crowley et al., 1989]. Unlike the highly variable ion drifts during the different substorm phases, the neutral wind speeds do not change greatly and the maximum wind speed remains about $350 \mathrm{~m} / \mathrm{s}$, which is about half of the maximum convection speed before and after the substorm onset. Plate 2 also shows that the overall wind pattern rotates counter-clockwise with UT. Such a universal time variation in the neutral wind pattern is due to the offset of geomagnetic pole from the geographic pole, which introduces a diurnal variation of ionospheric convection in geographic coordinates [Killeen and Roble, 1984]. Although the ion-drag force due to ionospheric convection has a strong influence on the high-latitude thermospheric wind, the overall neutral flow is determined mainly by the balance between ion drag, pressure, Coriolis, and advective forces [e.g., Killeen and Roble, 1984; Fuller-Rowell and Rees, 1984]. During the 2 days under present investigation, there was a series of substorms, as manifested by the variations in the auroral activity indices (see Figure 2a). The average sub- 


\section{Height-Integrated "Convection Heating"}

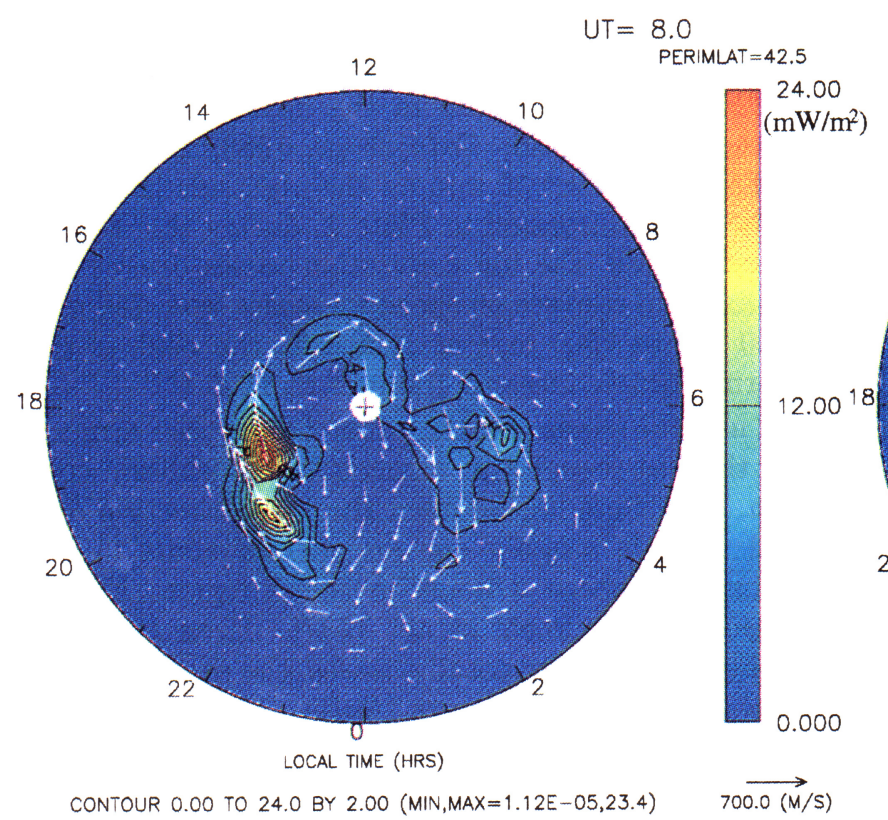

(a)

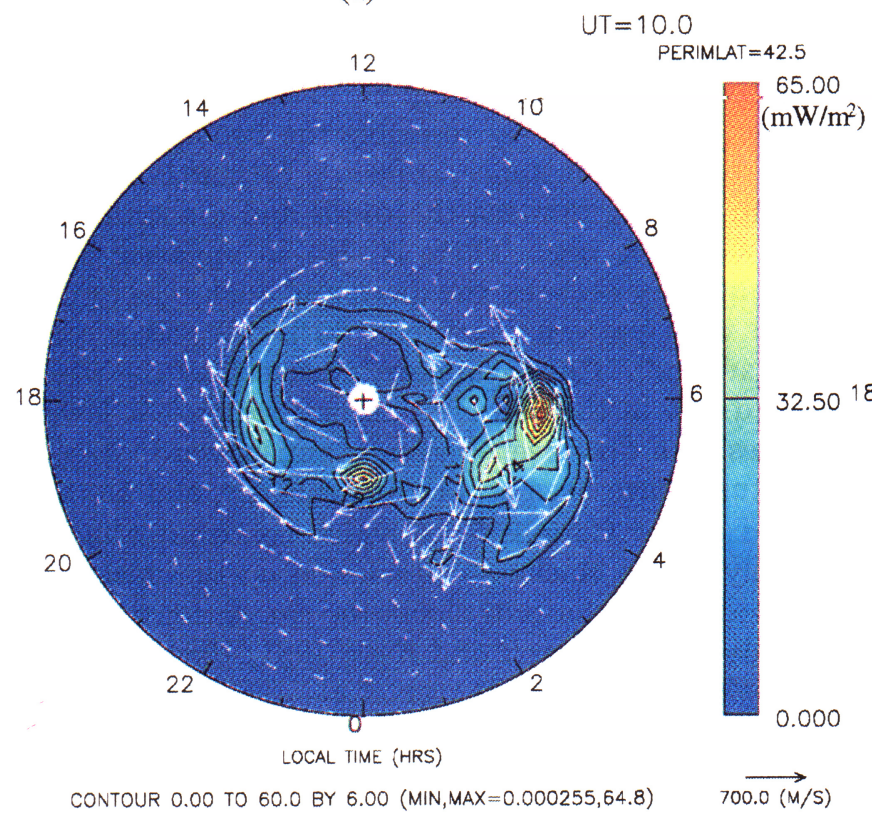

(c)

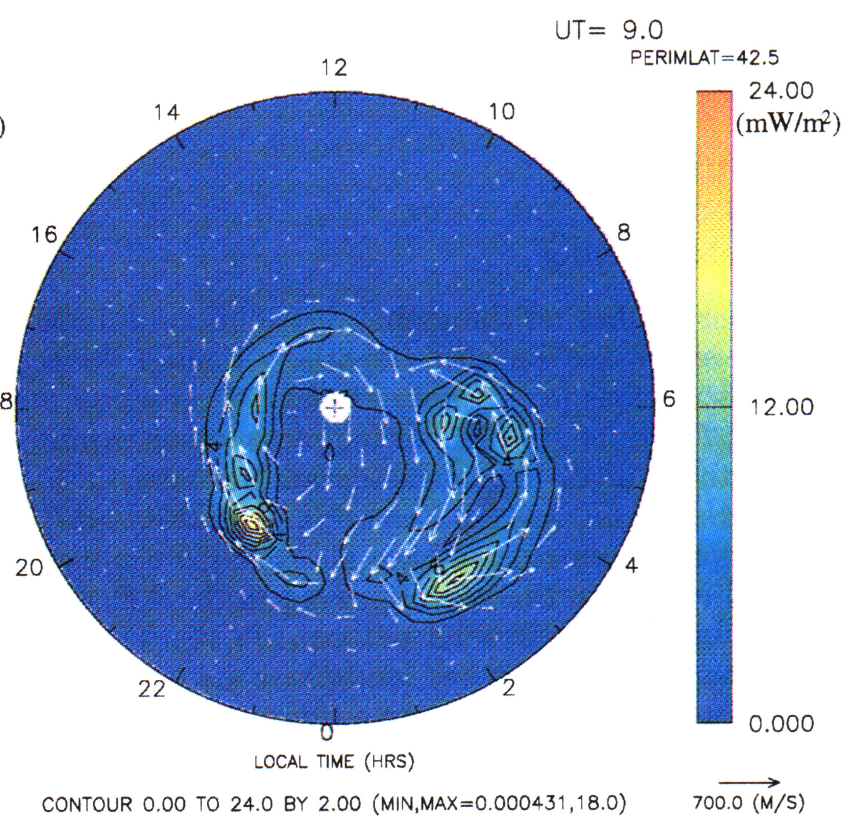

(b)

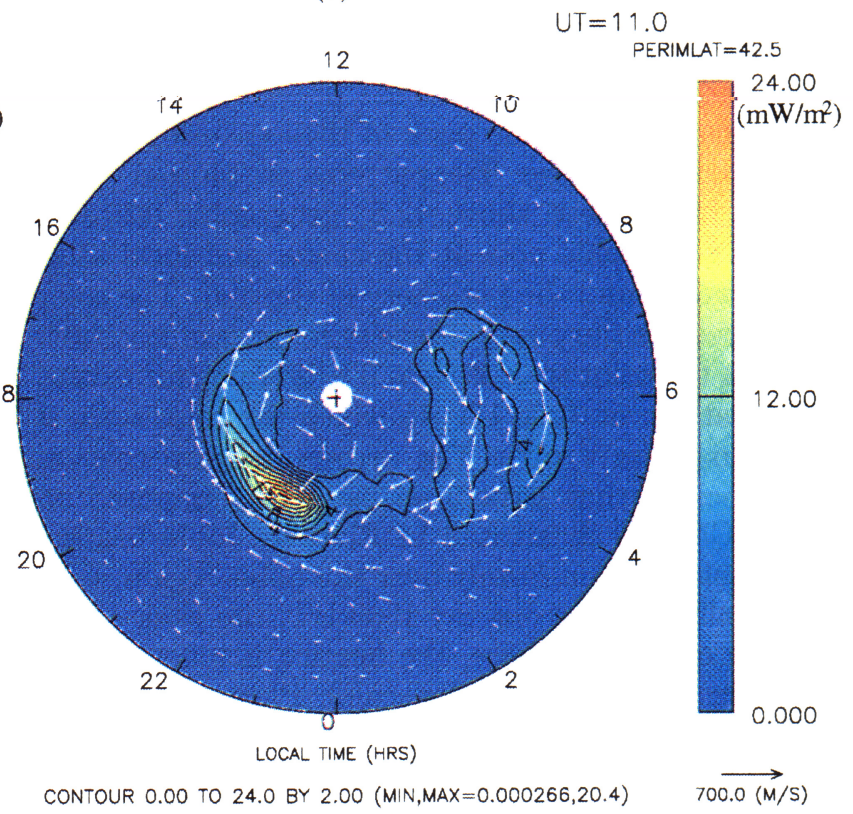

(d)

Plate 1. Hourly patterns of the height-integrated "convection heating" (i.e., $\varepsilon_{0}$ in (3)) derived at (a) $0800 \mathrm{UT}$; (b) $0900 \mathrm{UT}$; (c) $1000 \mathrm{UT}$; and (d) $1100 \mathrm{UT}$ on March 29, 1992, respectively. The patterns are plotted in the northern hemisphere above $42.5^{\circ}$ geographic latitude, with the geographic north pole at the center of the pattern and local solar time shown around the periphery of the dial. The maximum and minimum values of the heating are given underneath each pattern. The color scale represents the power intensity in units of $\mathrm{mW} / \mathrm{m}^{2}$. The arrows indicate the ion drift velocities that have been externally imposed on the TIGCM. A scale factor is given at the lower right of the pattern.

storm recurrence period is about 4 hours. Therefore, because of the large residual forces, the neutral wind does not have a chance to follow the ion convection exactly.

The distribution of total height-integrated Joule heating is presented in Plate 3, which is the sum of "convection heating" and "wind heating." Plate 3 resem- bles Plate 1 in terms of general structures. However, the total Joule heating rate is noticeably smaller than the "convection heating" rate. The heating patterns of Plate 3 are roughly of an oval shape, centered around the magnetic pole (as indicated by the asterisk) which is about $79^{\circ} \mathrm{N}$ and $71^{\circ} \mathrm{W}$ in geographical coordinates. There also exist pronounced spatial and temporal vari- 


\section{Height-Integrated "Wind Heating"}

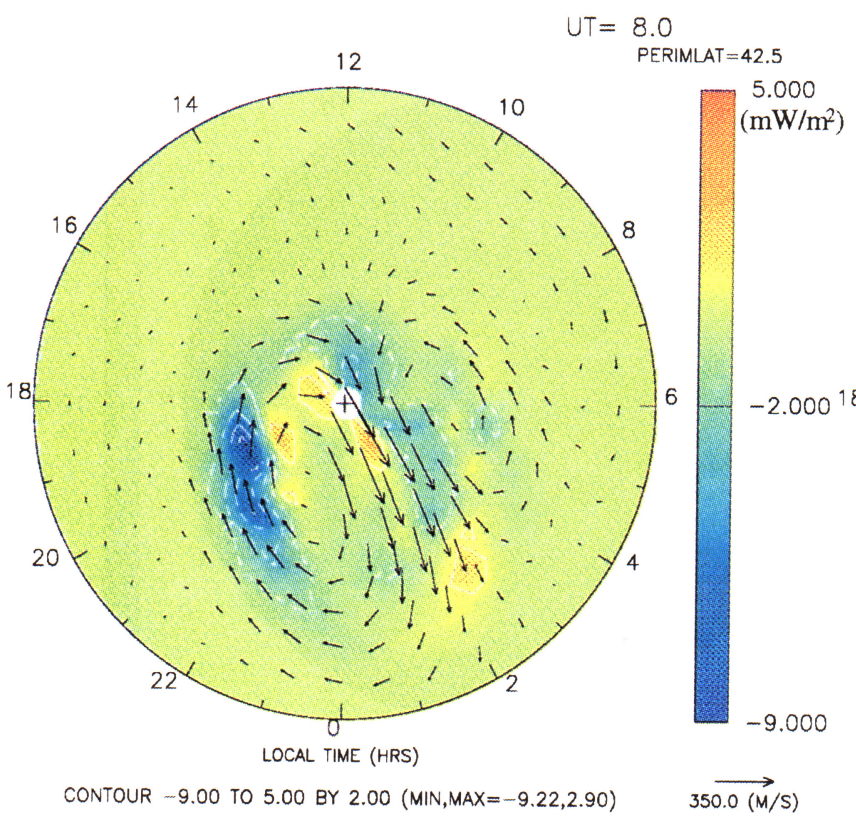

(a)

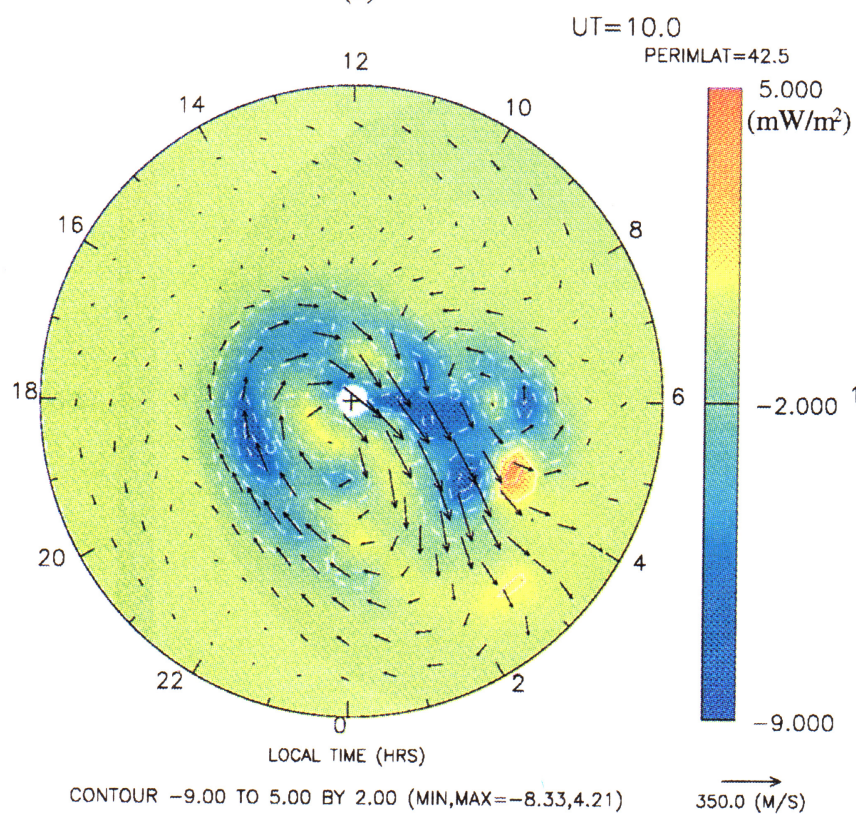

(c)

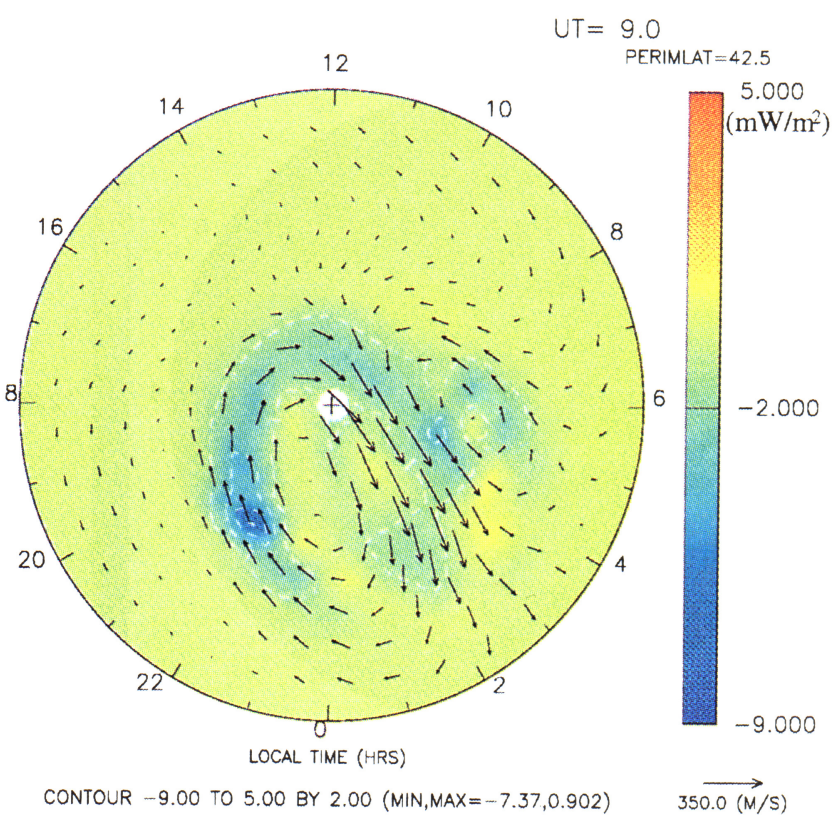

(b)

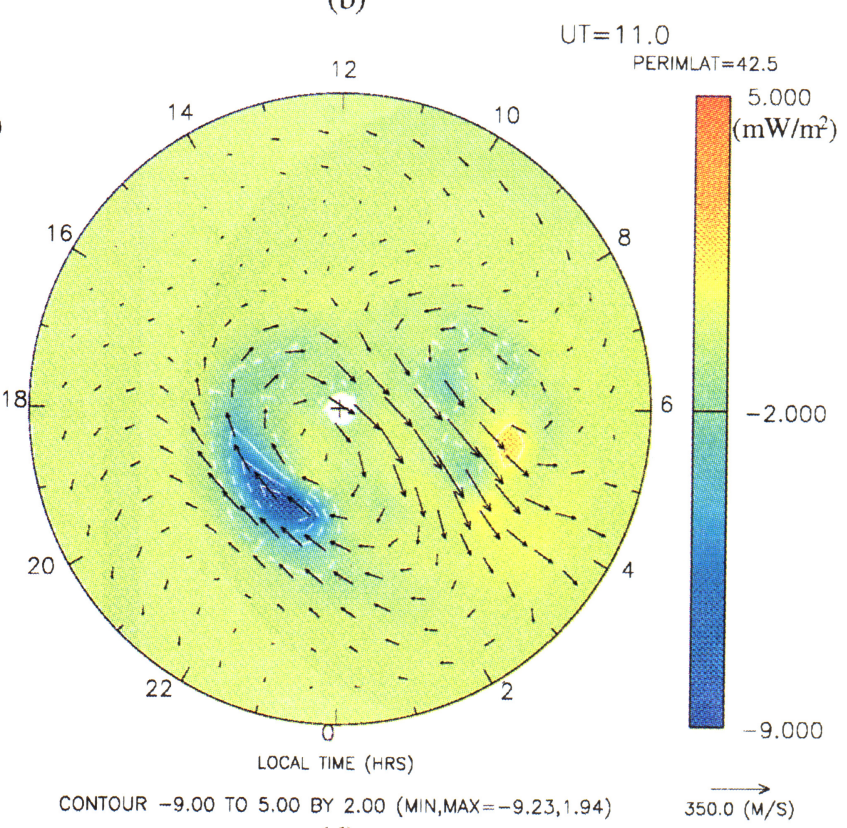

(d)

Plate 2. Hourly patterns of the height-integrated "wind heating" (i.e., $\varepsilon_{1}$ in (3)), with the same format as Plate 1. The arrows now indicate the effective neutral wind velocities (see text for details).

ations in the distribution of the total Joule heating. During relatively quiet periods (e.g., Plates $3 \mathrm{a}$ and $3 \mathrm{~d}$ ), the intense heating is colocated with the eastward electrojet in the evening sector; while during disturbed periods (Plates $3 \mathrm{~b}$ and $3 \mathrm{c}$ ), the Joule heating remains about the same in the evening sector but becomes more intensified in the morning sector, which corresponds to the westward electrojet. In addition, at the peak of the substorm, an isolated hot spot, which may correspond to the so-called substorm electrojet [Kamide et al., 1994], is seen near local midnight.

\subsection{Mechanical Power}

Plate 4 shows the distribution of the mechanical power exerted on the neutral wind by the Ampere force (or ion drag), that is, the height-integral of $\varepsilon_{W}$ in (2). The color scale is from -3 to $5 \mathrm{~mW} / \mathrm{m}^{2}$. Positive values indicate where the winds are in the same direction as the dragging force so that they act as a load on the magnetospheric dynamo, in the frame of reference of the rotating Earth. Negative values indicate where the winds are in the opposite direction to the dragging force 


\section{Height-Integrated Joule Heating}

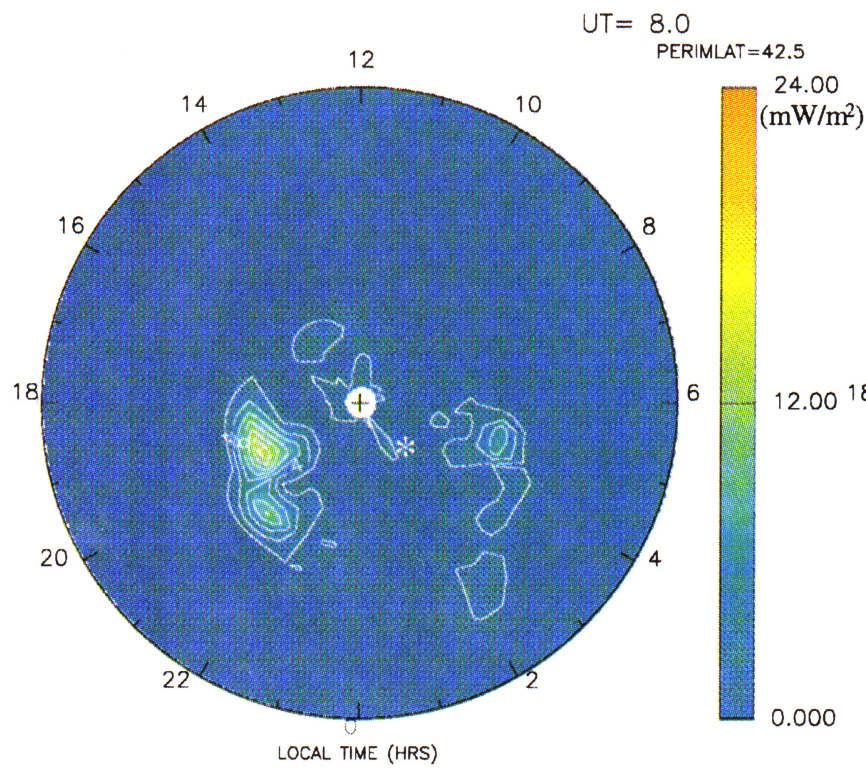

CONTOUR 0.00 TO 24.0 BY 2.00 (MIN,MAX=0.00117,14.3)

(a)

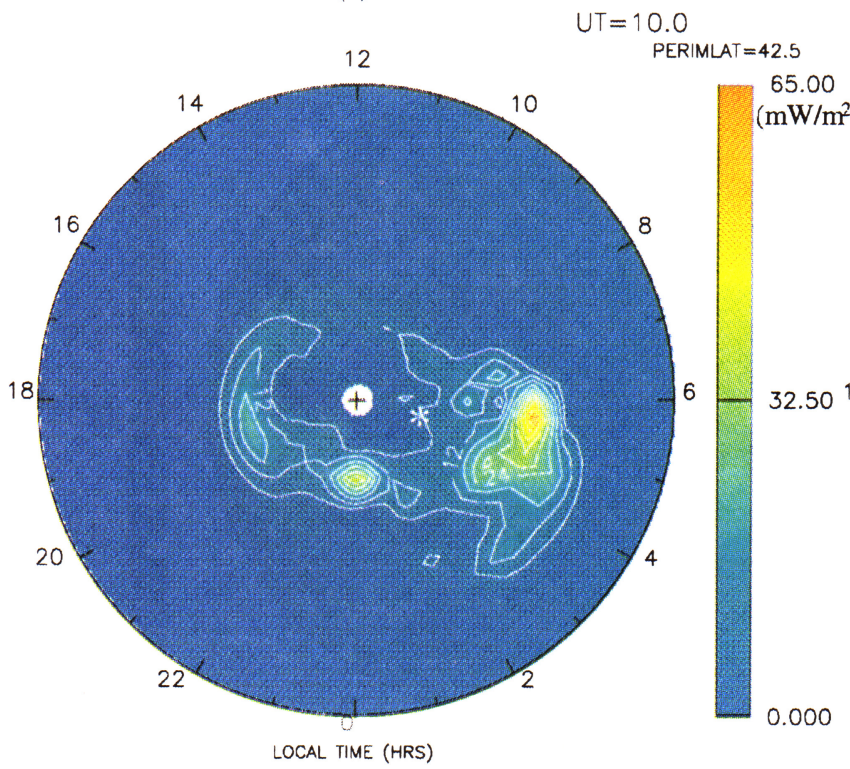

CONTOUR 0.00 TO 60.0 BY 6.00 (MIN,MAX $=0.00638,59.4$ )

(c)

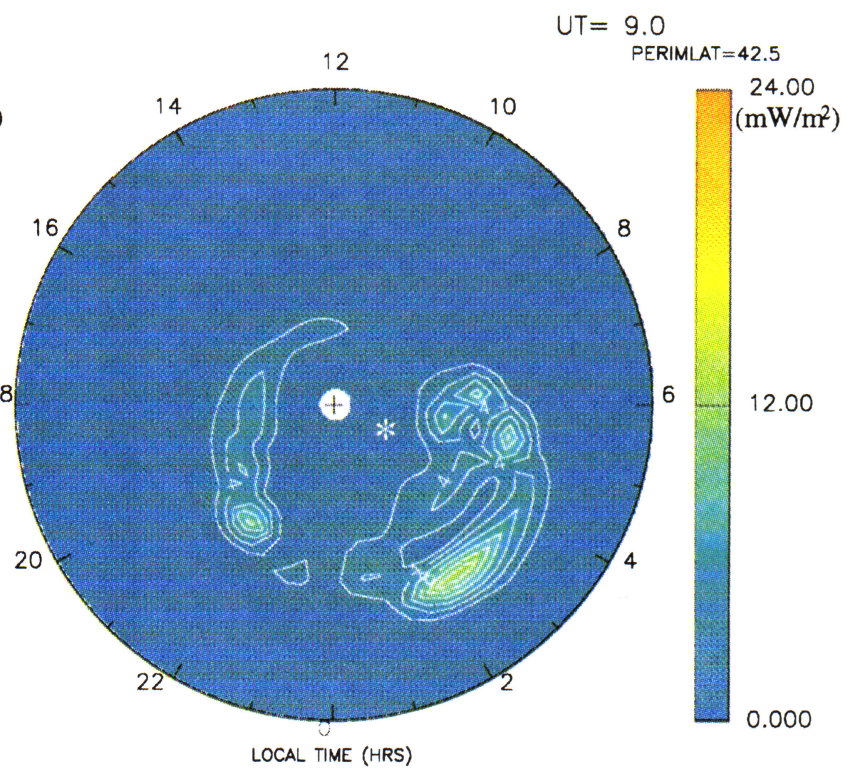

CONTOUR 0.00 TO 24.0 BY 2.00 (MIN,MAX $=0.00175,13.7$ )

(b)

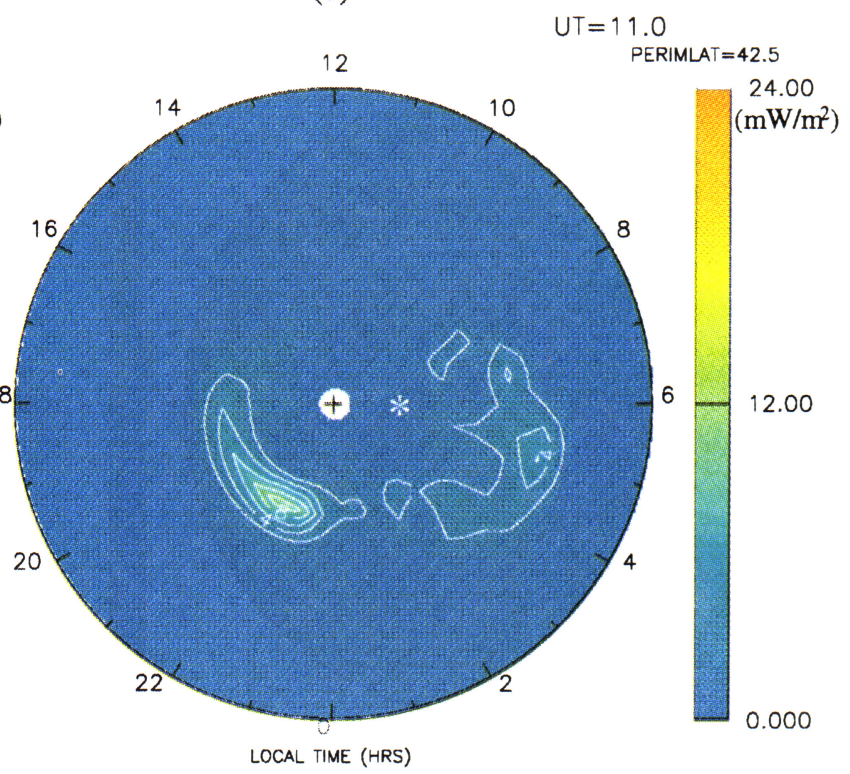

CONTOUR 0.00 TO 24.0 BY 2.00 (MIN,MAX $=0.00525,11.2$ )

(d)

Plate 3. Hourly patterns of the height-integrated Joule heating, that is, the sum of "convection heating" and "wind heating." The asterisks indicate the geomagnetic pole.

and therefore they act as a generator. Though the magnitude of the mechanical power is small compared to the Joule heating, Plate 4 clearly shows the thermospheric dynamo feature in the polar region. At $0800 \mathrm{UT}$, prior to the onset of the substorm, the ionosphere is still recovering from the previous substorm. The distribution of the mechanical power (Plate 4a) shows that the winds flow against the ion-drag force over nearly half of the polar cap. The hemispheric integral of the mechanical power above $42.5^{\circ}$ geographic latitude is $-0.91 \mathrm{GW}$.
This net negative value of the mechanical power represents the neutral wind dynamo effect; however, the magnitude is trivial in comparison with the hemispheric integral of the total Joule heating, which is $55 \mathrm{GW}$.

\subsection{Electromagnetic Energy Dissipation}

The electromagnetic energy dissipation/generation in the ionosphere, as shown in Plate 5, is the sum of the total Joule heating and the mechanical power exerted on 


\section{Height-Integrated Mechanical Power}

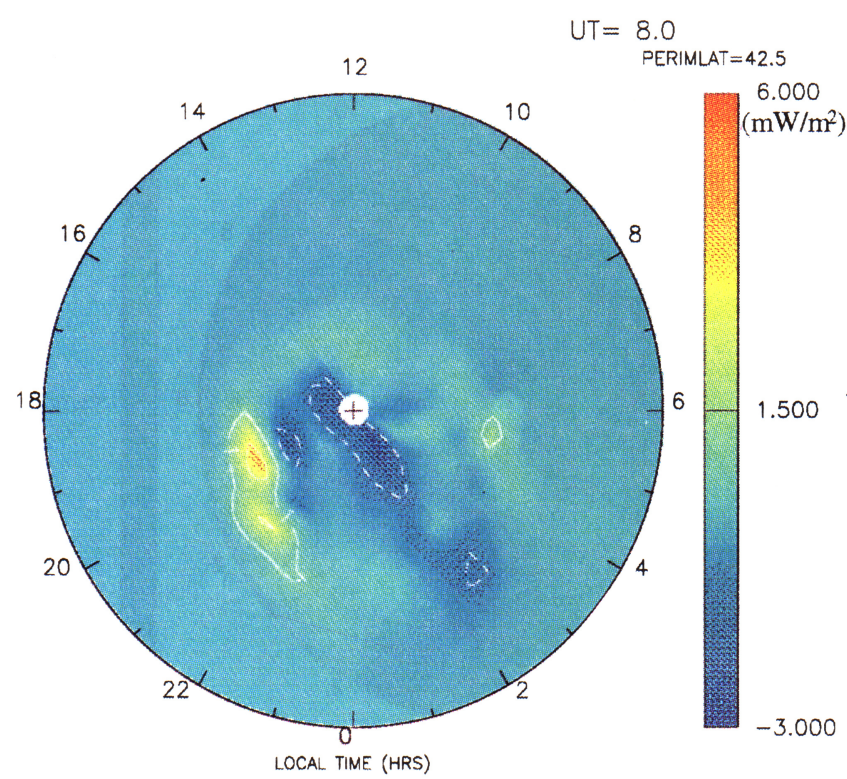

CONTOUR -3.00 TO 5.00 BY 2.00 (MIN, MAX $=-2.69,4.22$ )

(a)

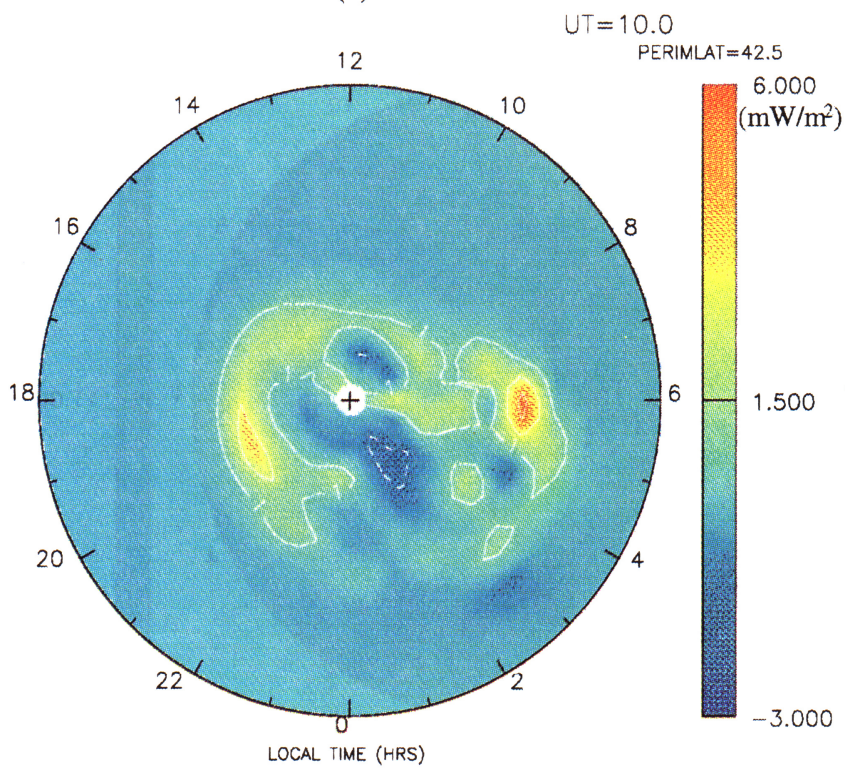

CONTOUR -3.00 TO 5.00 BY 2.00 (MIN,MAX $=-1.36,5.72)$

(c)

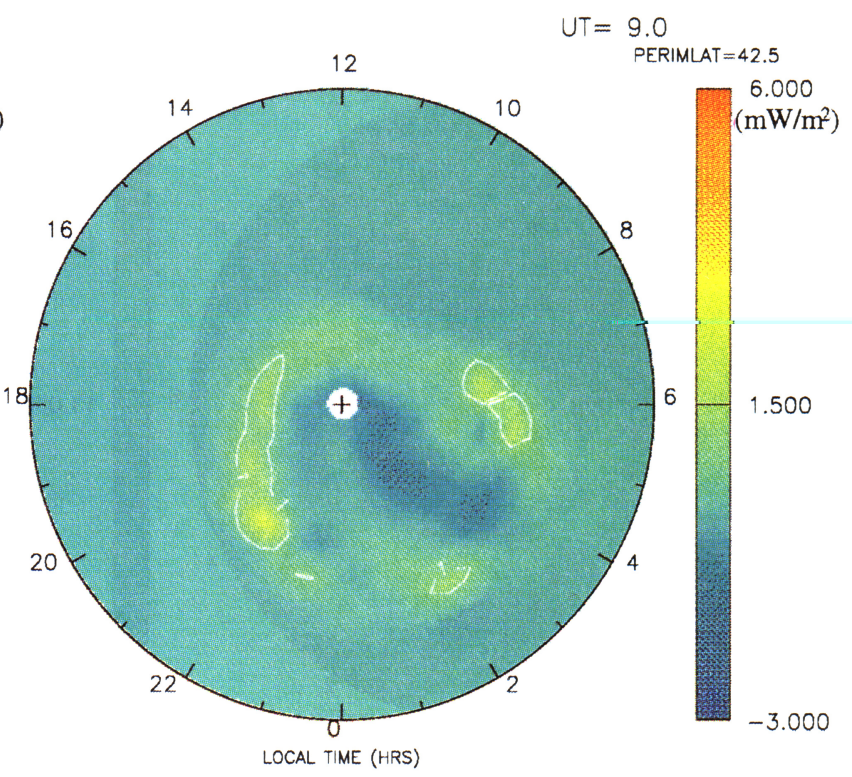

CONTOUR -3.00 TO 5.00 BY 2.00 (MIN,MAX $=-0.944,2.94$ )

(b)

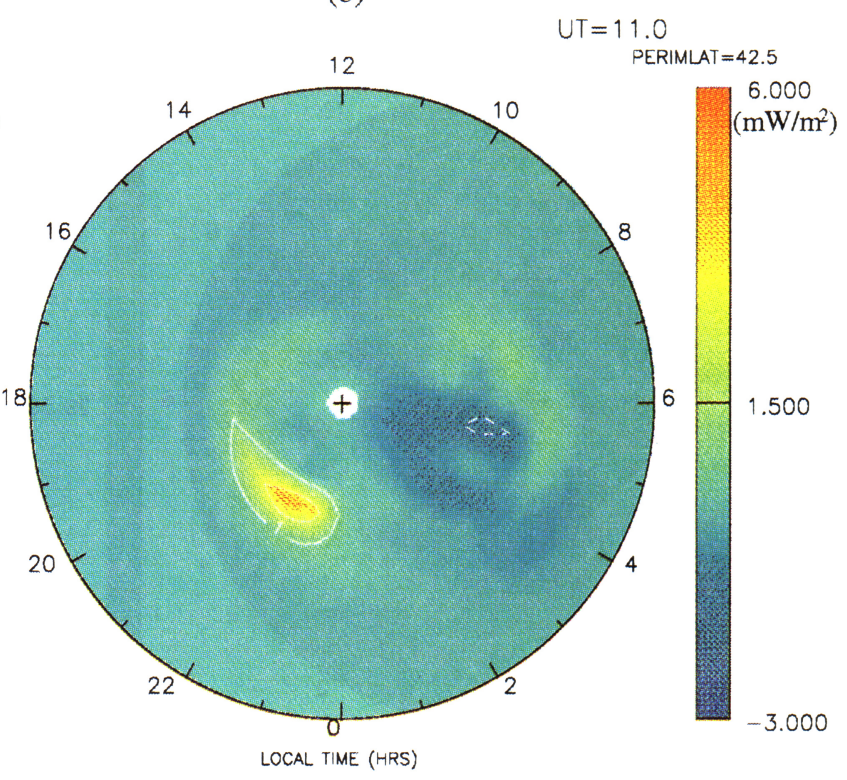

CONTOUR -3.00 TO 5.00 BY 2.00 (MIN,MAX $=-1.17,4.56)$

(d)

Plate 4. Hourly patterns of the height-integrated mechanical power, that is, $\varepsilon_{W}$ in (2).

the winds by the Ampere force $\vec{J} \times \vec{B}$. The distribution of the total energy dissipation (shown as solid contours) is very similar to that of the total Joule heating in terms of both spatial structure and magnitude. This indicates that the majority of the magnetospheric energy dissipation goes to heating and only a small portion of energy goes to accelerate the winds. There is also a very small amount of power generated by the neutral wind dynamo (shown as dashed contours) at the center of the polar cap as well as in the midlatitude region. However, the total energy provided by the wind dynamo is insignificant compared to that by the magnetospheric dynamo.

An accurate estimate of the energy transfer rate or energy dissipation/generation rate is important in understanding the magnetosphere-ionosphere-thermosphere coupling processes. Under steady state conditions (at timescales of greater than $1 \mathrm{~min}$ ), the energy dissipation or generation rate is equal to the electromagnetic energy flux flowing into or out of the ionosphere. Kelley et al. [1991] calculated the energy flux to the 


\section{Height-Integrated Energy Dissipation/Generation}

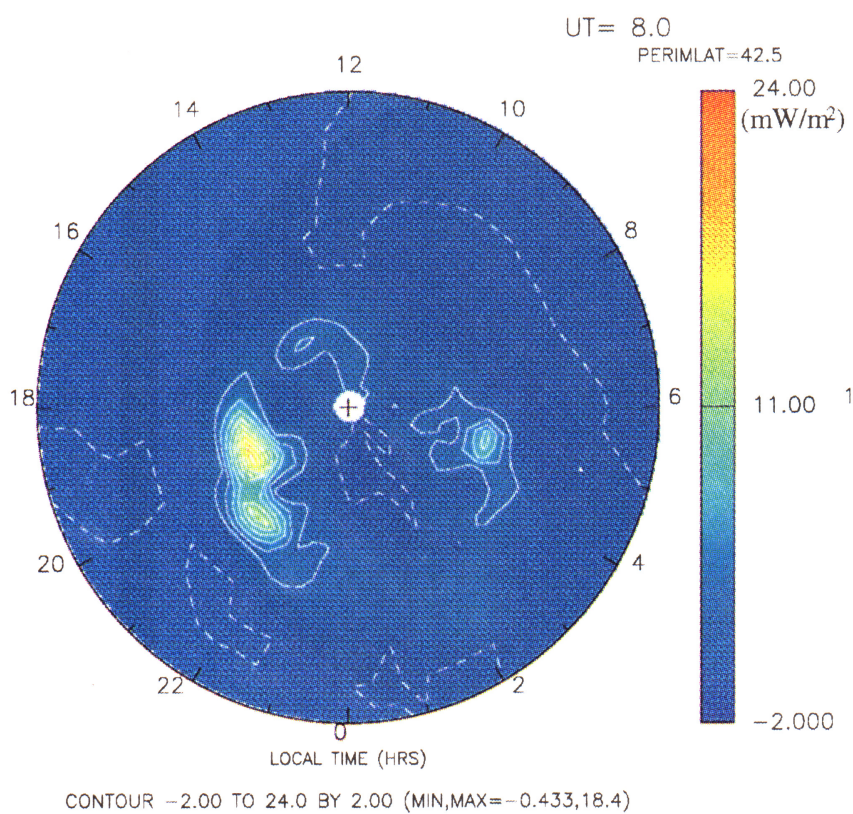

(a)

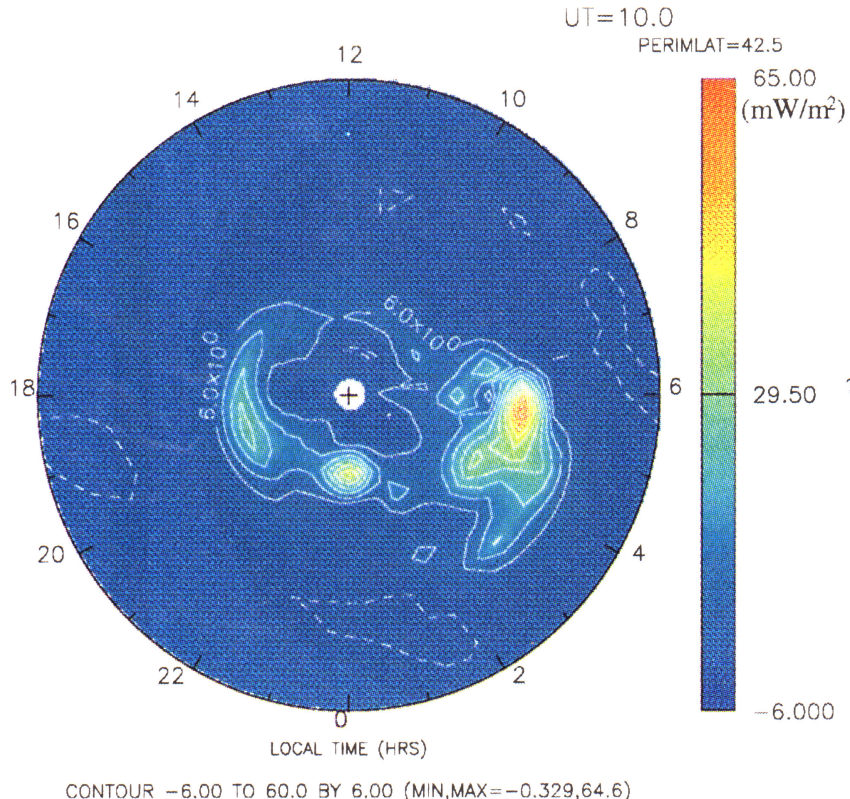

(c)

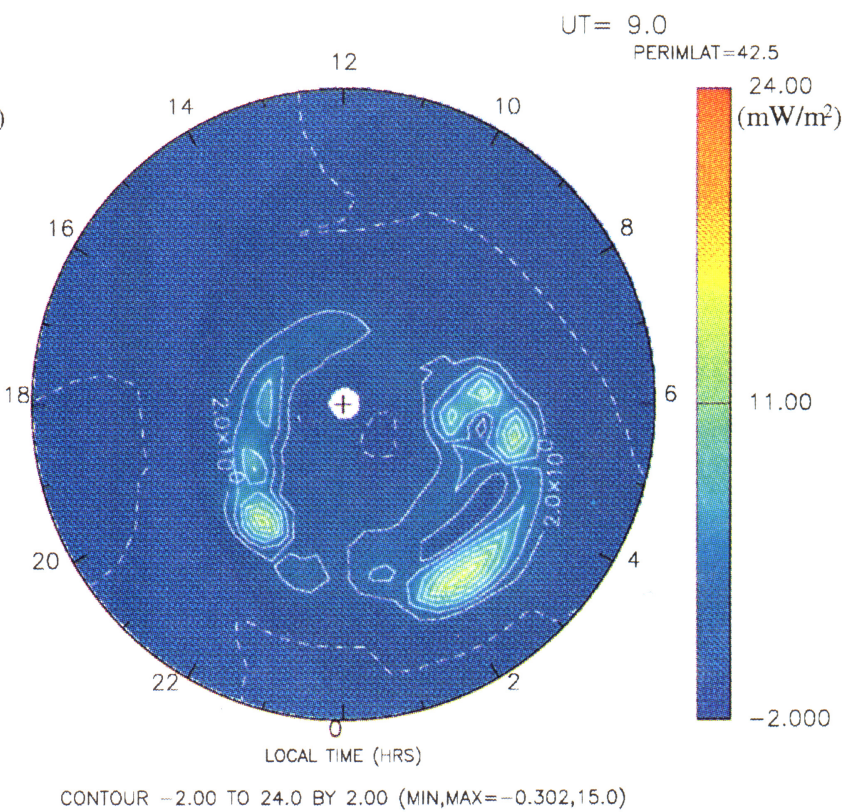

(b)

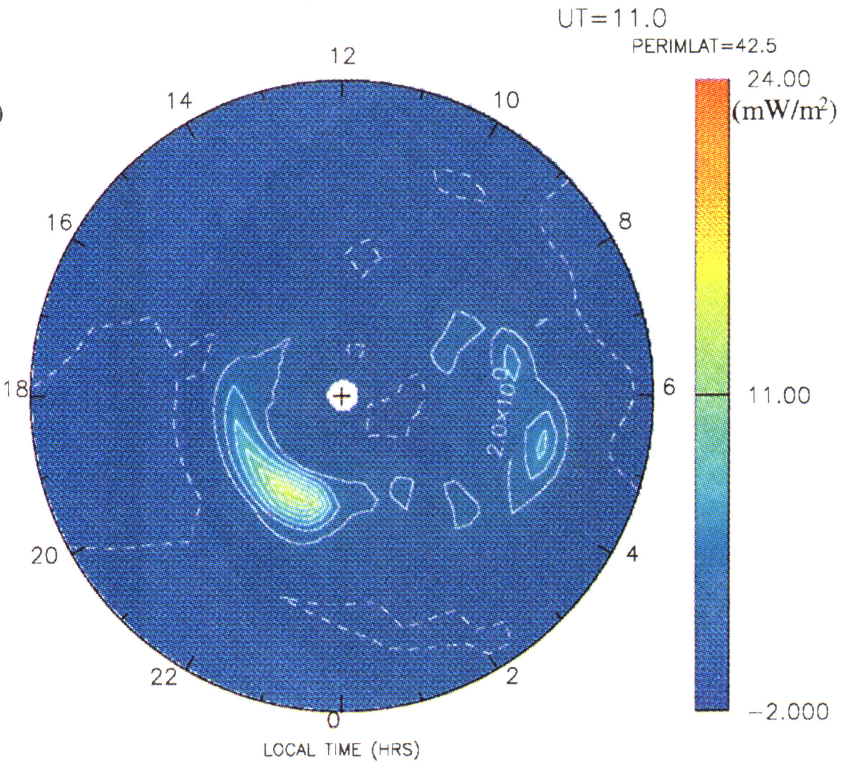

CONTOUR -2.00 TO 24.0 BY $2.00($ MIN, MAX $=-0.275,15.7)$

(d)

Plate 5. Hourly patterns of the height-integrated energy dissipation generation, that is, the sum of Joule heating and mechanical power.

high-latitude ionosphere by using measurements from the HILAT satellite. They found upward energy fluxes in some localized auroral regions, suggesting a neutral wind dynamo. Such dynamo effects of the neutral wind have also been simulated by Thayer and Vickrey [1992] and Deng et al. [1993]. They first calculated the height integrals of $\varepsilon_{0}$ and $\varepsilon_{U}$ separately, and considered them as the electric energy fluxes from the magnetospheric dynamo and the neutral wind dynamo, respectively. The net energy flux was then obtained by adding the two fluxes together. The net energy fluxes thus ob- tained can point upward in some high-latitude regions, indicating a dominating neutral wind dynamo. Especially during post-storm period, the whole polar cap can be overwhelmed by the upward energy fluxes [Deng et al., 1993]. However, as has been discussed in the previous section, because of the interaction between electric fields and neutral velocities, the two dynamos cannot be treated as independent sources. Accordingly, the distribution of the total energy flux in Plate 5 is rather calculated from first principles, that is, the energy conservation law. It is also worth noting that the post- 


\section{Field-Aligned Current (ion drift)}

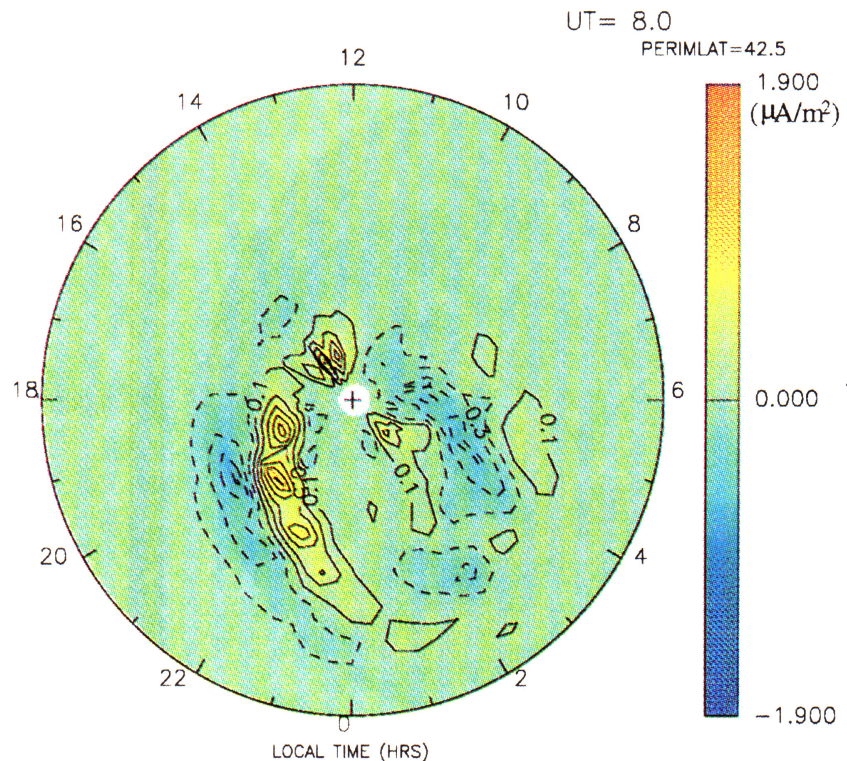

CONTOUR -1.90 TO 1.90 BY $0.200($ MIN,MAX $=-0.734,1.12)$

(a)

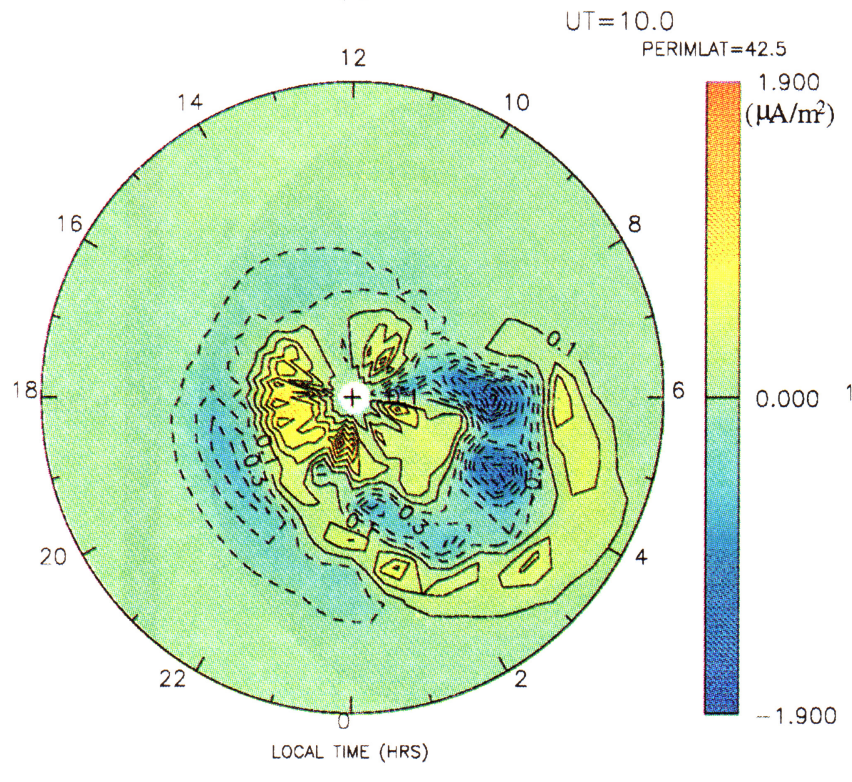

CONTOUR - 1.90 TO 1.90 BY $0.200($ MIN,MAX $=-1.81,1.37)$

(c)

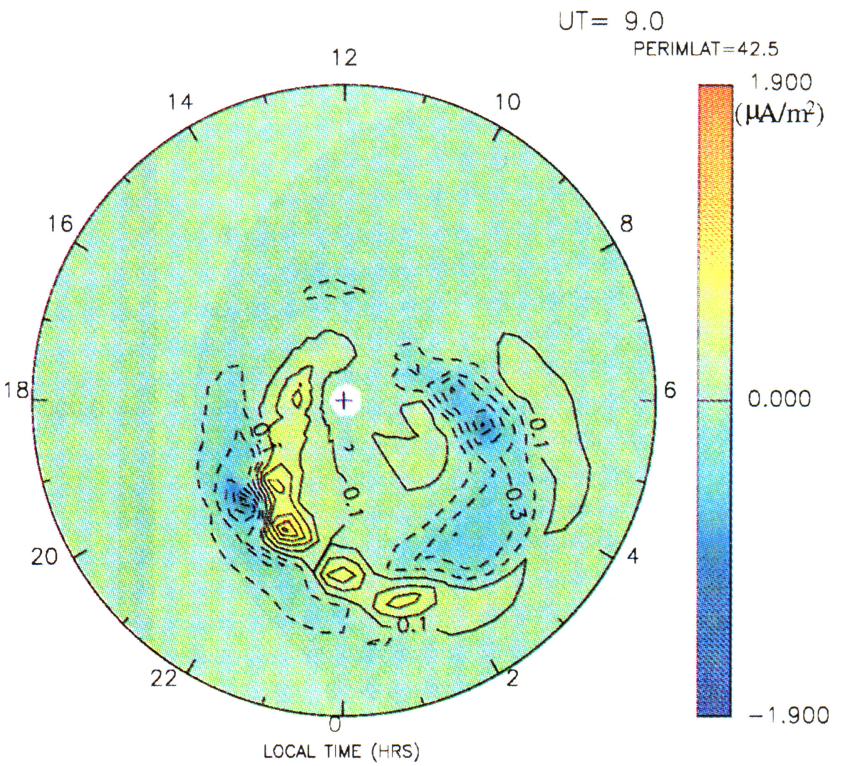

CONTOUR - 1.90 TO 1.90 BY $0.200($ MIN,MAX $=-1.00,1.17)$

(b)

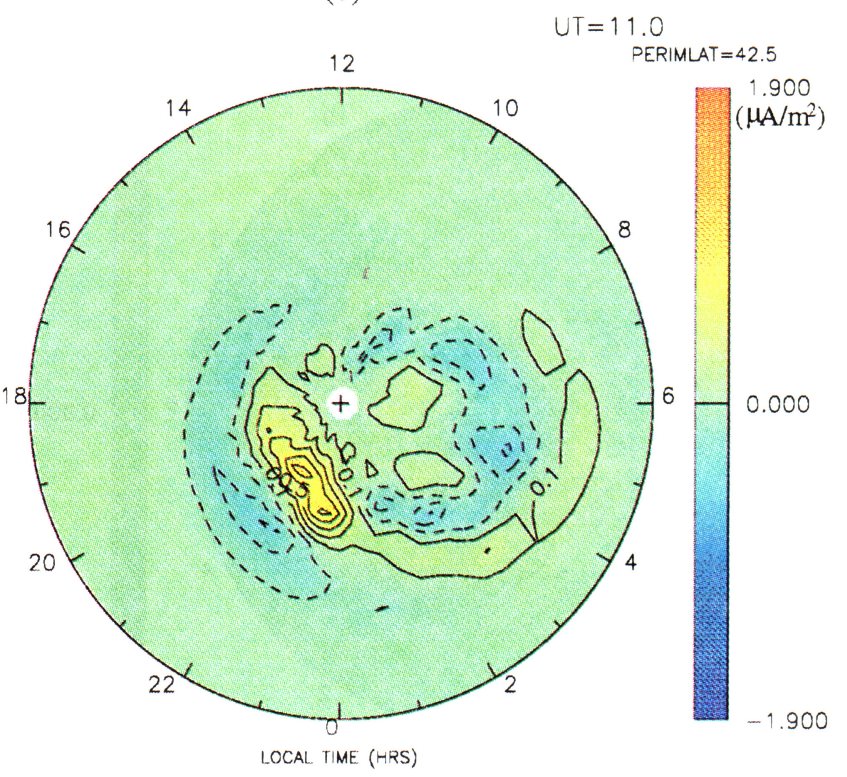

CONTOUR -1.90 TO 1.90 BY 0.200 (MIN, MAX $=-0.545,1.00)$

(d)

Plate 6. Hourly patterns of the field-aligned current (ion drift) density driven by the ionospheric convection. The color scale represents the current density in units of $\mu \mathrm{A} / \mathrm{m}^{2}$.

storm simulation by Deng et al. [1993] corresponded to extreme geomagnetic conditions, in which the crosspolar-cap potential drop was artificially reduced from 150 to $11 \mathrm{kV}$ immediately following the storm so that the wind velocity actually exceeded the convection velocity in most of the polar cap region.

\subsection{Field-Aligned Currents}

Plate 6 presents the distribution of the field-aligned current density driven by the convection. In spite of the small-scale structures, the general features illustrated here are similar to the statistical patterns of Iijima and Potemra [1978]: upward region 1 and downward region 2 currents on the duskside, and downward region 1 and upward region 2 currents on the dawnside. Of particular interest is the pattern derived at $1000 \mathrm{UT}$, in which not only is the current density intensified but also an upward field-aligned current sheet appears poleward of the dawnside downward region 1 current sheet. Along with the region 2 current from the dawnside, they form 


\section{Field-Aligned Current (neutral wind)}

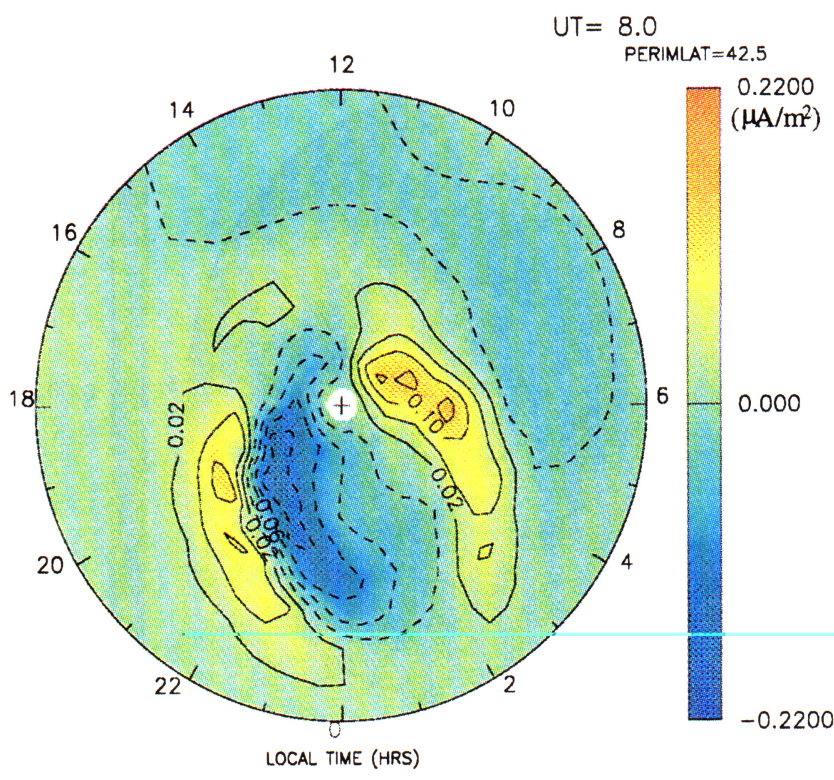

CONTOUR -0.220 TO 0.220 BY 0.0400 (MIN,MAX $=-0.165,0.157$ )

(a)

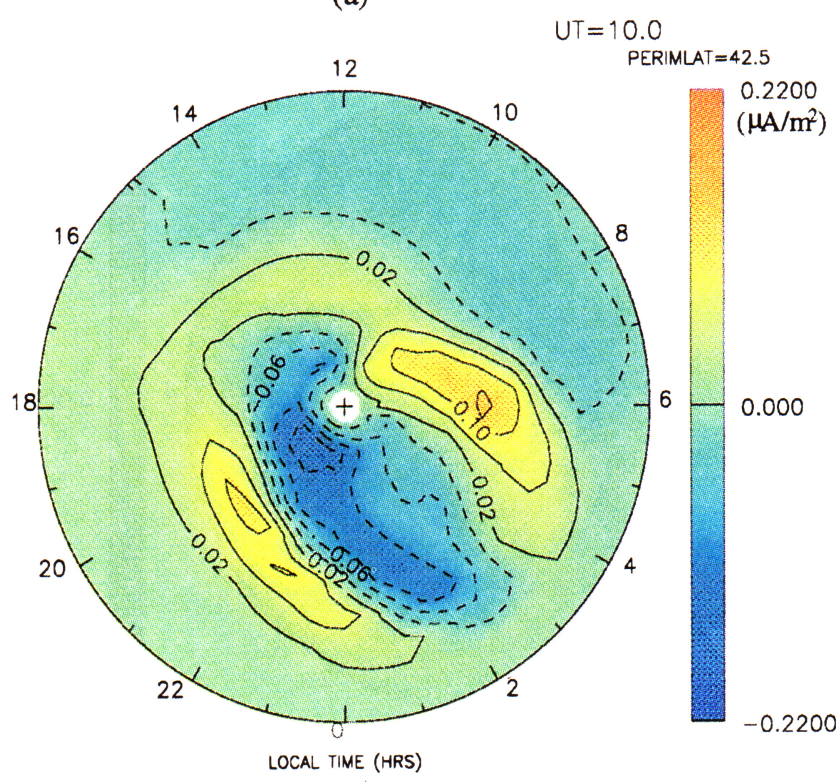

CONTOUR -0.220 TO 0.220 BY $0.0400($ MIN,MAX $=-0.166,0.152)$

(c)

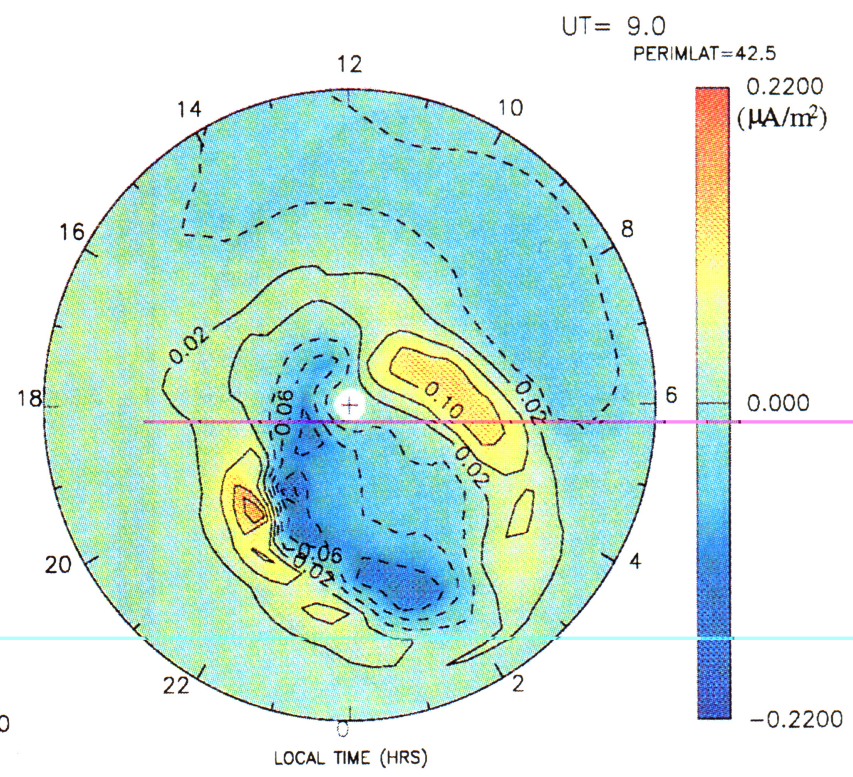

CONTOUR -0.220 TO 0.220 BY $0.0400($ MIN,MAX $=-0.167,0.173)$

(b)

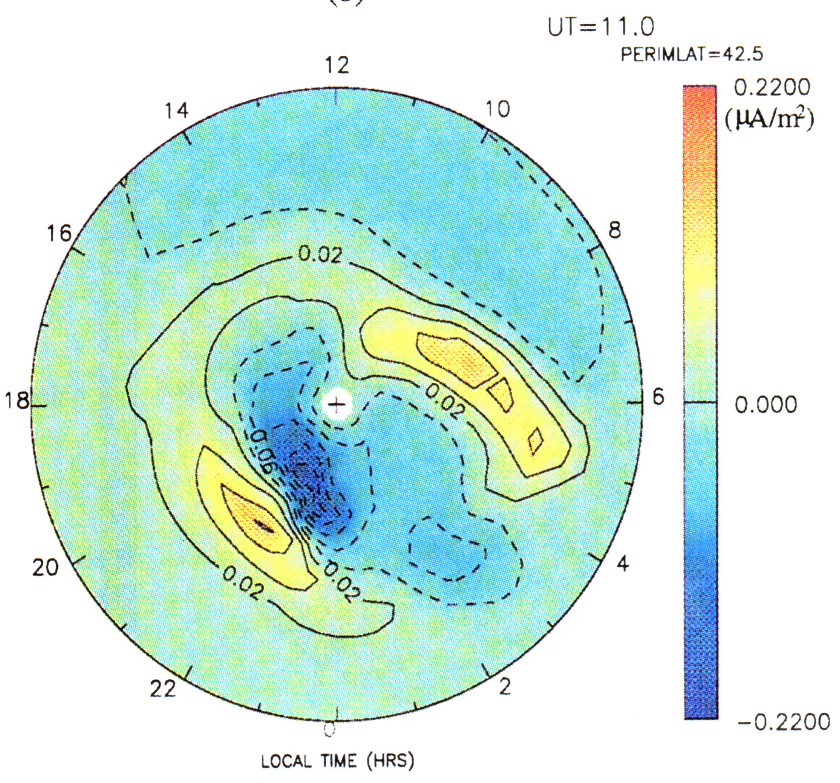

CONTOUR -0.220 TO 0.220 BY 0.0400 (MIN,MAX $=-0.217,0.144)$

(d)

Plate 7. Similar to Plate 6, but for the field-aligned current driven by the neutral wind.

a triple current sheet in the early morning sector (in geographic coordinates). This kind of current distribution is often found to be associated the westward traveling surge, one of the ionospheric manifestations of a substorm [Opgenoorth et al., 1980, 1983; Baumjohann et al., 1981].

The neutral-wind-driven field-aligned currents shown in Plate 7 are more organized and consist of two current sheets surrounding the magnetic pole. The patterns also show no apparent change during the course of substorm. However, the field-aligned currents driven by the neutral wind tend to flow in the opposite direction to those driven by the ion convection, i.e., downward region 1 and upward region 2 on the duskside, and upward region 1 and downward region 2 on the dawnside. The magnitude of the field-aligned current density driven by the wind is of the order of $10^{-7} \mathrm{~A} / \mathrm{m}^{2}$. At $0800 \mathrm{UT}$ (the pre-substorm phase), the ratio of the peak downward current density driven by the wind to that driven by the convection is about 0.22 ; whereas, at $1000 \mathrm{UT}$ (the peak of the substorm), this ratio decreases to 0.09. Although the current density is weaker, the neutral-wind-driven 
field-aligned currents expands to a wider latitude range than the convection-driven currents, which are mainly confined within the auroral oval. Since the field-aligned currents that flow into and out of the ionosphere, integrated over the globe, should be the same in order to maintain charge neutrality, the total field-aligned current can be considered as one-half the integral of the absolute value of $j_{\|}$over the hemisphere. On the average for the two days, the hemispheric integral of the total field-aligned current driven by the wind is about $27 \%$ of the total field-aligned current driven by the convection.

Lyons et al. [1985] modeled the neutral wind effect on the ionospheric current system. They found that, after magnetospheric convection ceases, the neutral wind can drive significant ionospheric currents for about 6 hours. The field-aligned currents driven by the neutral winds flow out of the ionosphere on the dawnside and into the ionosphere on the duskside, same as the inner current sheet shown in Plate 7 . The estimated mean value of $j_{\|}$is of the order of $10^{-8} \mathrm{~A} / \mathrm{m}^{2}$, which is about one order of magnitude smaller than that from our calculation. The field-aligned current density estimated by Lyons et al. is rather crude. They have assumed a uniform ionosphere, so that the contribution to field-aligned current due to the ionospheric conductivity gradient is not included in their study. A recent simulation by Deng et al. [1993] also shows that during the recovery phase of a major storm the Hall current driven by the neutral winds could account for up to $80 \%$ of the total ionospheric current, when the magnetospheric forcing was cut off almost completely. Their magnitude of $j_{\|}$(mainly driven by the neutral winds) as well as its distribution are similar to those shown in Plate 7 (note that their patterns are plotted in magnetic coordinates).

\subsection{Comparisons of Global Energy Inputs}

The top panel of Figure 2 shows the $A U, A L$, and $A E$ indices deduced from the measurements of 43 ground stations located between $55^{\circ}$ and $76^{\circ}$ magnetic latitudes. However, the longitudinal coverage of the ground magnetometer data is limited for this particular period, because of a big data gap over the Russian area. The bottom panel of Figure 2 shows the four different energy inputs integrated above $42^{\circ}$ geographic latitude in the northern hemisphere, with the solid line for the electromagnetic energy dissipation, the dashed line for the total Joule heating rate, the dotted line for the "convection heating," and the dashed-dotted line for the electron precipitation. The difference between the dashed and dotted lines represents the contribution of the neutral wind to the heating, that is, the "wind heating." The magnitude of the hemisphere-integrated "wind heating" increases with the $A E$ index, and so does the total hemisphere-integrated Joule heating rate. As a result, the ratio between the "wind heating" and the total Joule heating shows no apparent dependence on the $A E$ index. During this 2-day period, the average value of this ratio is -0.28 , which means that the
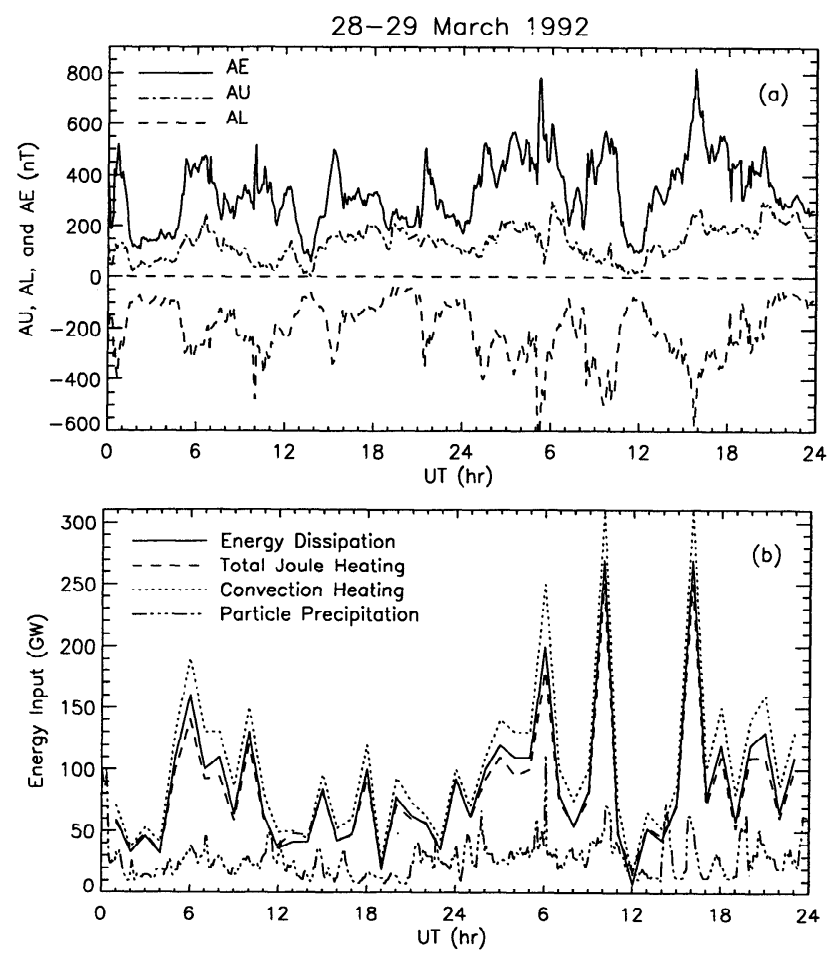

Figure 2. (a) The distribution the $A U, A L$, and $A E$ indices throughout the 2-day period of March 28 and 29, 1992. (b) The distributions of the different energy inputs integrated above $42.5^{\circ}$ geographic latitude over the northern hemisphere for these 2 days.

neutral winds reduce the Joule heating by about $28 \%$. On the other hand, comparison between the dashed and solid lines reveals that the total hemisphere-integrated electromagnetic energy dissipation, in general, is only slightly larger than the total Joule heating. The average ratio of the total Joule heating to the total electromagnetic energy dissipation is about 0.94 . Thus the majority $(94 \%)$ of the electromagnetic energy dissipated to the ionosphere is converted to thermal energy and only a small portion $(6 \%)$ of it goes to mechanical energy to accelerate the neutrals.

In addition to electromagnetic energy dissipation (mainly via Joule heating), energy is also deposited to the ionosphere through the precipitation of energetic particles. Observations have shown that the particle energy deposition rate can at times greatly exceed the Joule heating rate, particularly within an auroral arc [e.g., Evans et al., 1977; Vickrey et al., 1982; Kelley et al., 1991]. However, globally, Joule heating is larger than particle energy dissipation because it extends over a wider range of latitudes [Ahn et al., 1983a; Doyle et al., 1986; Richmond et al., 1990]. Figure 2b shows that the energy input from the precipitating particles is similar to the electromagnetic energy input during quiet periods, but significantly smaller during disturbed periods. On the average for these two days, the ratio between the hemisphere-integrated electromagnetic energy input and particle energy input is about 4 . This result is consistent with those obtained by $A h n$ et al. [1983a] and Richmond et al. [1990]. 
The hemispheric energy dissipation is related to the auroral activity index. We have calculated the correlation coefficients of electromagnetic energy dissipation versus the $A L, A U$, and $A E$ indices, respectively. The best correlation is found between the energy dissipation and the $A E$ index, with a correlation coefficient $r=0.76$ (compared to $r=0.58$ against $|A L|$ and $r=0.55$ against $A U$ ). To further quantitatively examine the relation between the electromagnetic energy input and the $A E$ index, Figure 3 shows scatterplots of the energy dissipation versus $A E$, with the solid line representing a linear fit in the top panel and an exponential fit in the bottom panel. The linear regression analysis yields a slope of $0.33 \mathrm{GW} / \mathrm{nT}$. The least squares fitting of data to an exponential function is slightly better than the simple linear fitting by reducing the standard deviation $\sigma$ from 36.2 to $34.0 \mathrm{GW}$. The exponential fitting yields a dependence of energy input on the $A E$ index to the power 1.645, with a variation \pm 0.006 .

Previous studies on the quantitative relation between global Joule heating and the $A E$ index have derived different linear proportionality factors. A proportionality factor was found to be $0.21 \mathrm{GW} / \mathrm{nT}$ for the period January 18 and 19, 1984 [Richmond et al., 1990], 0.23 $\mathrm{GW} / \mathrm{nT}$ for the 3 days of March 17-19, 1978 [Ahn et $a l ., 1983 \mathrm{a}]$, and $0.33 \mathrm{GW} / \mathrm{nT}$ for July 23 and 24, 1983 [Ahn et al., 1989]. The difference in the proportionality factors by the independent studies may be due to the difference in estimating Joule heating. A seasonal variation can have a direct effect on the ionospheric conductivities, which in turn affect Joule heating. Even for the
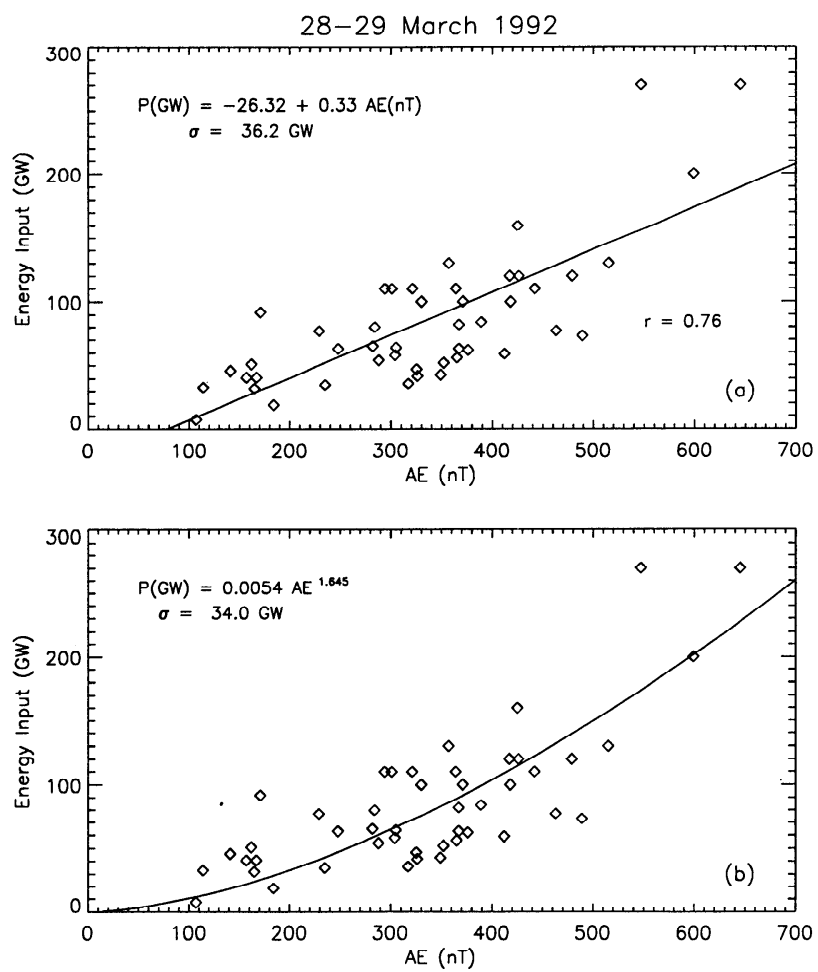

Figure 3. Scatter plots of the energy dissipation versus the $A E$ index, The solid line shows a linear fit in the top panel, and an exponential fit in the bottom panel. The $\sigma$ represents the standard deviation of the fitting. same period of March 17-19, 1978, a linear regression analysis by Baumjohann and Kamide [1984] derived a factor of $0.32 \mathrm{GW} / \mathrm{nT}$, which is about $40 \%$ larger than that found by Ahn et al. [1983a]. This difference has been ascribed to the different ionospheric conductivities used in the two studies. In the study by $A h n$ et al. [1983a], the ionospheric conductivities were estimated from ground magnetic perturbations [Ahn et al., 1983b], whereas the study by Baumjohann and Kamide [1984] adopted the empirical conductivity model of Spiro et al. [1982].

It is clear that the accuracy of estimates of Joule heating is limited by the accuracy in estimating the ionospheric conductivities, especially for those studies using the magnetic-inversion technique [e.g., $A h n$ et al., 1983a, 1989; Baumjohann and Kamide, 1984]. The TIGCM solves for the ionospheric structure giving global distributions of electron and major ion densities, and electron and ion temperatures. Thus, for given fluxes of auroral electrons, it provides a realistic estimate of the ionospheric conductivity. Furthermore, in those studies mentioned above, the Joule heating rate, or more accurately, the "convection heating" rate, was considered as the total electromagnetic energy input. As has been illustrated in Figure 2b, the "convection heating" rate does not equal the real electromagnetic energy input.

The solar wind is the ultimate power source which is responsible for the electrodynamic processes in the magnetosphere and ionosphere. One can estimate the coupling efficiency between the solar wind and Earth's magnetosphere by comparing the solar wind energy input with the energy dissipation into the magnetosphere. During the 2-day period, the upstream solar wind conditions were monitored by the IMP 8 satellite only from 1320 to 1930 UT on March 29, 1992 (the solar wind data were kindly provided by A. Lazarus). For this 6-hour interval, the average solar wind density $\rho$ is about 10 $\mathrm{amu} / \mathrm{cm}^{3}$ and the average solar wind velocity $v$ is 350 $\mathrm{km} / \mathrm{s}$. Assuming that the effective cross-section area of the magnetosphere $A$ is $\pi\left(15 \mathrm{R}_{E}\right)^{2} \sim 3 \times 10^{16} \mathrm{~m}^{2}$, the available solar-wind power is thus $\frac{1}{2} \rho v^{3} A \sim 10^{13} \mathrm{~W}$. For the same interval, the total average energy (including both electromagnetic energy and particle precipitation) dissipated into the high-latitude ionosphere is $1.5 \times 10^{11}$ $\mathrm{W}$. Therefore only $1.5 \%$ of the solar wind energy penetrates into the ionosphere.

We should point out that in this study we have quantitatively estimated large-scale energy dissipation/generation channels. Due to the limitations of data coverage as well as spatial resolutions in both AMIE and TIGCM, we are unable to resolve accurately the smallscale energy inputs, such as those associated with discrete auroral arcs. The electric field is often depressed within an arc where the particle precipitation is most intense, so that Joule heating tends to be reduced there [e.g., Evans et al., 1977]. The AMIE procedure does not reproduce this effect, since it tends to smear out the discrete arc features. We cannot quantify the net effect of auroral arcs on the total energy dissipation at 
present time; however, we do not expect the estimate of the global energy dissipation derived in this study to be altered significantly due to the presence of auroral arcs.

\section{Summary and Conclusions}

We have used realistic time-dependent high-latitude patterns of the ionospheric convection and auroral particle precipitation derived from AMIE as inputs to the TIGCM model to investigate the magnetosphere-ionosphere-thermosphere coupling processes during the period of March 28 and 29, 1992. Our study has led to the following conclusions:

1. The electromagnetic energy dissipated from the magnetosphere to the ionosphere is converted into thermal and mechanical energy. The results of our study show that majority (94\%) of this energy input is converted to Joule heating, and only a small portion (6\%) goes to accelerate the neutrals.

2. Joule heating is nonuniformly distributed over the high-latitude region, with some localized hot spots. During relative quiet periods, the heating is mainly found in the dusk sector associated with the eastward electrojet. During disturbed periods, the heating intensifies in the morning sector associated with the westward electrojet.

3. The influence of neutral wind on Joule heating can become significant. On the average, the wind dynamo can have approximately a $28 \%$ negative effect on the heating.

4. The field-aligned currents driven by the neutral wind tend to flow in the opposite direction as those driven by the plasma convection. On the average, the wind-driven field-aligned currents amount to $27 \%$ of the total field-aligned currents driven by the plasma convection.

5. The global energy input from particle precipitation is similar to the global electromagnetic energy input during quiet periods, but is substantially less during disturbed periods. On average, the ratio between the two energy inputs is about a factor of 4 .

We recognize that the NCAR TIGCM model used in this study does not take into account the electrodynamic feedback of the thermospheric neutral wind to the overall magnetospheric electric fields. A fully coupled magnetosphere-ionosphere-thermosphere electrodynamic model would be required to take this feedback into account. Such a model remains to be developed.

Acknowledgments. We wish to acknowledge the CEDAR (Coupling, Energetics and Dynamics of Atmospheric Regions) Data Base at the National Center for Atmospheric Research (NCAR) for providing the Sondrestrom incoherent scatter radar data. Both facilities are supported by the National Science Foundation (NSF). The Johns Hopkins University Applied Physics Laboratory HF radar at Goose Bay, Labrador, is supported in part by the NSF Division of Atmospheric Sciences under NSF grant ATM9003860 and in part by the National Aeronautics and Space
Administration (NASA) under grant NAG5-1099. The IMAGE magnetometer network is supported by the Finnish Meteorological Institute. We thank L. Morris at the World Data Center for selecting the ground magnetometer data, the Canadian Space Agency and T. Hughes at the National Research Council of Canada for providing data from the CANOPUS magnetometer array, the Auroral Observatory at the University of Tromso, Norway, for contributing data from the Norwegian Arctic Stations, P. Sutcliffe at the Hermanus Magnetic Observatory in South Africa for submitting the Hermanus magnetometer data, C. G. Maclennan and L. J. Lanzerotti of AT\&T Bell Laboratories for providing data from their ground stations at Iqaluit (FRB) in Canada, and at McMurdo (MCM) and South Pole (SPA) in the Antarctic. The magnetometer installation at Iqaluit is partially supported by grant DPP-89-21094 to Allan Wolfe of NYCTC from Division of Polar Programs of the NSF. The IMP-8 IMF data were kindly provided by R. Lepping at NASA Goddard Space Flight Center, and the IMP-8 plasma data were provided by A. Lazarus at MIT. The DMSP ion drift and particle data were provided by F. Rich and W. Denig at the Phillips Laboratory, the NOAA 12 particle data were provided by D. Evans at SEL/NOAA, the EXOS D satellite data were provided by A. Mutsuoka and T. Mukai at the Institute of Space and Astronautical Science, and by $\mathrm{T}$. Nagatsuma and H. Fukunishi at the Upper Atmosphere and Space Research Laboratory of Tohoku University in Japan, and the UARS data were provided by R. Frahm and J. D. Winningham at SWRI, and by D. Chenette at Lockheed. We would like thank E. C. Ridley for her efforts in TIGCM development, and we are indebted to B. Foster for developing the IDL codes to generate the color figures used in this paper. This study was supported in part by NSF grant 93-SFA.1, the NASA Space Physics Theory Program and NASA grants W-17,384 and W-18,536, and by the NASA UARS program through a subcontract (11048) with SWRI. The National Center for Atmospheric Research is sponsored by the National Science Foundation.

The Editor thanks D. J. Knudsen and another referee for their assistance in evaluating this paper.

\section{References}

Ahn, B. -H., S. -I. Akasofu, and Y. Kamide, The Joule heat production rate and the particle energy injection rate as a function of the geomagnetic indices $A E$ and $A L, J$. Geophys. Res., 88, 6275, 1983a.

Ahn, B. -H., R. M. Robinson, Y. Kamide, and S. -I. Akasofu, Electric conductivities, electric fields and auroral energy injection rate in the auroral ionosphere and their empirical relations to the horizontal magnetic disturbances, Planet. Space Sci., 31, 641, 1983b.

Ahn, B. -H., H. W. Kroehl, Y. Kamide, D. J. Gorney, S. I. Akasofu, and J. R. Kan, The auroral energy deposition over the polar ionosphere during substorms, Planet. Space Sci., 37, 239, 1989.

Baker, D. N., R. D. Zwickl, S. J. Bame, E. W. Hones Jr., B. T. Tsurutani, E. J. Smith, and S. -I. Akasofu, An ISEE 3 high time resolution study of interplanetary parameter correlations with magnetospheric activity, J. Geophys. Res., 88, 6230, 1983.

Banks, P. M., Magnetospheric processes and the behaviour of the neutral atmosphere, Space Res., 12, 1051, 1972.

Banks, P. M., J. C. Foster, and J. R. Doupnik, Chatanika radar observations relating to the latitudinal and local time variations of Joule heating, J. Geophys. Res., 86, $6869,1981$. 
Baumjohann, W., and Y. Kamide, Hemispherical Joule heating and the $A E$ indices, J. Geophys. Res., 89, 383, 1984.

Baumjohann, W., R. J. Pellinen, H. J. Opgenoorth, and E. Nielsen, Joint two-dimensional observations of ground magnetic and ionospheric electric fields associated with auroral zone currents: Current systems associated with local auroral break-ups, Planet. Space Sci., 29, 431, 1981.

Blanc, M., and A. D. Richmond, The ionospheric disturbance dynamo, J. Geophys. Res., 85, 1669, 1980.

Chenette, D. L., D. W. Datlowe, R. M. Robinson, T. L. Schumaker, R. R. Vondrak, and J. D. Winningham, Atmospheric energy input and ionization by energetic electrons during the geomagnetic storm of 8-9 November 1991, Geophys. Res. Lett., 20, 1323, 1993.

Cowley, S. W. H., J. P. Morelli, and M. Lockwood, Dependence of convective flows and particle precipitation in the high-latitude dayside ionosphere on the $X$ and $Y$ components of the interplanetary magnetic field, J. Geophys. Res., 96, 5557, 1991.

Crowley, G., B. A. Emery, R. G. Roble, H. C. Carlson Jr., and D. J. Knipp, Thermospheric dynamics during September 18-19, 1984, 1, Model simulations, J. Geophys. Res., 94, 16,925, 1989.

Deng, W., T. L. Killeen, A. G. Burns, and R. G. Roble, The flywheel effect: Ionospheric currents after a geomagnetic storm, Geophys. Res. Lett., 18, 1845, 1991.

Deng, W., T. L. Killeen, A. G. Burns, R. G. Roble, J. A. Slavin, and L. E. Wharton, The effects of neutral inertia on ionospheric currents in the high-latitude thermosphere following a geomagnetic storm, J. Geophys. Res., 98, 7775, 1993.

Dickinson, R. E., E. C. Ridley, and R. G. Roble, A threedimensional, time-dependent general circulation model of the thermosphere, J. Geophys. Res., 86, 1499, 1981.

Doyle, M. A., W. J. Burke, D. A. Hardy, P. F. Bythrow, F. J. Rich, and T. A. Potemra, A simple model of auroral electrodynamics compared with HILAT measurements, $J$. Geophys. Res., 91, 6979, 1986.

Etemadi, A., S. W. H. Cowley, M. Lockwood, B. J. I. Bromage, D. M. Willis, and H. Luhr, The dependence of high-latitude dayside ionospheric flows on the north-south component of the IMF, a high time resolution correlation analysis using EISCAT "POLAR" and AMPTE UKS and IRM data, Planet. Space Sci., 36, 471, 1988.

Evans, D. S., N. C. Maynard, J. Troim, T. Jacobsen, and A. Egeland, Auroral vector electric field and particle comparisons, 2, Electrodynamics of an arc, J. Geophys. Res., 82, 2235, 1977.

Fesen, C. G., R. G. Roble, and E. C. Ridley, Thermospheric tides at equinox: Simulations with coupled composition and auroral forcings, 2, Semidiurnal component, J. Geophys. Res., 96, 3663, 1991.

Forbes, J. M., and M. Harel, Magnetosphere-thermosphere coupling: An experiment in interactive modeling, J. Geophys. Res., 94, 2631, 1989.

Forbes, J. M., R. G. Roble, and F. A. Marcos, Thermospheric dynamics during the March 22, 1979, magnetic storm, 2, Comparisons of model predictions with observations, J. Geophys. Res., 92, 6069, 1987.

Foster, J. C., J. M. Holt, R. G. Musgrove, and D. S. Evans, Ionospheric convection associated with discrete levels of particle precipitation, Geophys. Res. Lett., 13, 656, 1986.

Foster, J. C., J. -P. St-Maurice, and V. J. Abreu, Joule heating at high latitudes, J. Geophys. Res., 88, 4885, 1983.

Fuller-Rowell, T. J., and D. S. Evans, Height-integrated Pedersen and Hall conductivity patterns inferred from the TIROS-NOAA satellite data, J. Geophys. Res., 92, 7606, 1987.
Fuller-Rowell, T. J., and D. Rees, A three-dimensional, time-dependent simulation of the global dynamical response of the thermosphere to a geomagnetic substorm, J. Atmos. Terr. Phys., 43, 701, 1981.

Fuller-Rowell, T. J., and D. Rees, Interpretation of an anticipated long-lived vortex in the lower thermosphere following simulation of an isolated substorm, Planet. Space Sci., 32, 69, 1984.

Hayakawa, H., et al., Electric field measurement on the Akebono (EXOS-D) satellite, J. Geomagn. Geoelectr., 42, $371,1990$.

Hays, P. B., T. L. Killeen, N. W. Spencer, L. E. Wharton, R. G. Roble, B. A. Emery, T. J. Fuller-Rowell, D. Rees, L. A. Frank, and J. D. Craven, Observations of the dynamics of the polar thermosphere, J. Geophys. Res., 89, 5597, 1984.

Heelis, R. A., The effects of interplanetary magnetic field orientation on the dayside high-latitude convection, J. Geophys. Res., 89, 2880, 1984.

Heelis, R. A., J. K. Lowell, and R. W. Spiro, A model of the high-latitude ionospheric convection pattern, J. Geophys. Res., 87, 6339, 1982.

Heppner, J. P., and N. C. Maynard, Empirical high-latitude electric field models, J. Geophys. Res., 92, 4467, 1987.

Iijima, T., and T. A. Potemra, Large-scale characteristics of field-aligned currents associated with substorms, J. Geophys. Res., 83, 599, 1978.

Kamide, Y., and H. W. Kroehl, A concise review of the utility of ground-based magnetic recordings for estimating the Joule heat production rate, Ann. Geophys., Ser. A, 5, 535, 1987.

Kamide, Y., R. D. Richmond, B. A. Emery, C. F. Hutchins, B. -H. Ahn, O. de la Beaujardiere, J. C. Foster, R. A. Heelis, H. W. Kroehl, F. J. Rich, and J. A. Slavin, Ground-based studies of ionospheric convection associated with substorm expansion, J. Geophys. Res., 99, 19,451, 1994.

Kelley, M. C., D. J. Knudsen, and J. F. Vickrey, Poynting flux measurements on a satellite: A diagnostic tool for space research, J. Geophys. Res., 96, 201, 1991.

Killeen, T. L., and R. G. Roble, An analysis of the highlatitude thermospheric wind pattern calculated by a thermospheric general circulation model, 1, Momentum forcing, J. Geophys. Res., 89, 7509, 1984.

Killeen, T. L., and R. G. Roble, An analysis of the highlatitude thermospheric wind pattern calculated by a thermospheric general circulation model, 2, Neutral parcel transport, J. Geophys. Res., 91, 11,291, 1986.

Killeen, T. L., P. B. Hays, G. R. Carignan, R. A. Heelis, W. B. Hanson, N. W. Spencer, and L. H. Brace, Ionneutral coupling in the high-latitude $F$ region: Evaluation of ion heating terms from Dynamics Explorer 2, J. Geophys. Res., 89, 7495, 1984.

Lockwood, M., A. P. van Eyken, B. J. I. Bromage, D. M. Willis, and S. W. H. Cowley, Eastward propagation of a plasma convection enhancement following a southward turning of the interplanetary magnetic field, Geophys. Res. Lett., 13, 72, 1986.

Lyons, L. R., A simple model for polar cap convection patterns and generation of $\Theta$ auroras, J. Geophys. Res., 90, 1561, 1985.

Lyons, L. R., T. L. Killeen, and R. L. Walterscheid, The neutral wind "flywheel" as a source of quiet-time, polarcap currents, Geophys. Res. Lett., 12, 101, 1985.

McCormac, F. G., T. L. Killeen, J. P. Thayer, G. Hernandez, C. R. Tschan, J. -J. Ponthieu, and N. W. Spencer, Circulation of the polar thermosphere during geomagnetically quiet and active times as observed by Dynamics Explorer 2, J. Geophys. Res., 92, 10,133, 1987.

Opgenoorth, H. J., R. J. Pellinen, H. Maurer, F. Küppers, W. J. Heikkila, K. U. Kaila, and P. Tanskanen, Ground- 
based observations of an onset of localized field-aligned currents during auroral breakup around magnetic midnight, J. Geophys. Res., 83, 101, 1980.

Opgenoorth, H. J., R. J. Pellinen, W. Baumjohann, E. Nielsen, G. Marklund, and L. Eliasson, Three-dimensional current flow and particle precipitation in a westward traveling surge (observed during the Barium-GEOS rocket experiment), J. Geophys. Res., 88, 3138, 1983.

Potemra, T. A., L. J. Zanetti, P. F. Bythrow, A. T. Y. Lui, and T. Iijima, $B_{y}$-dependent convection patterns during northward interplanetary field, J. Geophys. Res., 89, 9753, 1984.

Reiff, P. H., and J. L. Burch, IMF $B_{y}$-dependent plasma flow and Birkeland currents in the dayside magnetosphere, 2, A global model for northward and southward IMF, $J$. Geophys. Res., 90, 1595, 1985.

Rich, F. J., M. S. Gussenhoven, and M. E. Greenspan, Using simultaneous particle and field observations on a low altitude satellite to estimate Joule heat energy flow into the high latitude ionosphere, Ann. Geophys., Series A, 5 , $527,1987$.

Richmond, A. D., Assimilative mapping of ionospheric electrodynamics, Adv. Space Res., 12, 59, 1992.

Richmond, A. D., and Y. Kamide, Mapping electrodynamic features of the high-latitude ionosphere from localized observations: Technique, J. Geophys. Res., 93, 5741, 1988.

Richmond, A. D., and R. G. Roble, Electrodynamic effects of thermospheric winds from the NCAR thermospheric general circulation model, J. Geophys. Res., 92, 12,365, 1987.

Richmond, A. D., et al., An empirical model of quiet-day ionospheric electric fields at middle and low latitudes, $J$. Geophys. Res., 85, 4658, 1980.

Richmond, A. D., et al., Global measures of ionospheric electrodynamic activity inferred from combined incoherentscatter radar and ground magnetometer observations, $J$. Geophys. Res., 95, 1061, 1990.

Robinson, R. M., R. R. Vondrak, K. Miller, T. Dabbs, and D. Hardy, On calculating ionospheric conductances from the flux and energy of precipitating electrons, J. Geophys. Res., 92, 2565, 1987.

Roble, R. G., and E. C. Ridley, An auroral model for the NCAR thermospheric general circulation model (TGCM), Ann. Geophys., Ser. A, 5, 369, 1987.

Roble, R. G., J. M. Forbes, and F. A. Marcos, Thermospheric dynamics during the March 22, 1979, magnetic storm, 1, Model simulations, J. Geophys. Res., 92, 6045, 1987.

Roble, R. G., E. C. Ridley, A. D. Richmond, and R. E. Dickinson, A coupled thermosphere/ionosphere general circulation model, Geophys. Res. Lett., 15, 1325, $1988 \mathrm{~b}$.

Roble, R. G., T. L. Killeen, N. W. Spencer, R. A. Heelis, P. H. Reiff, and J. D. Winningham, Thermospheric dynamics during November 21-22, 1981: Dynamics Explorer measurements and thermospheric general circulation model predictions, J. Geophys. Res., 93, 209, 1988a.

Sojka, J. J., C. E. Rasmussen, and R. W. Schunk, An interplanetary magnetic field dependent model of the ionospheric convection electric field, J. Geophys. Res., 91, 11,281, 1986.

Spiro, R. W., P. H. Reiff, and L. J. Maher Jr., Precipitating electron energy flux and auroral zone conductances: An empirical model, J. Geophys. Res., 87, 8215, 1982.

Thayer, J. P., and J. F. Vickrey, On the contribution of the thermospheric neutral wind to high-latitude energetics, Geophys. Res. Lett., 19, 265, 1992.

Thayer, J. P., T. L. Killeen, F. G. McCormac, C. R. Tschan, J. -J. Ponthieu, and N. W. Spencer, Thermospheric neutral wind signatures dependent on the east-west component of the interplanetary magnetic field for northern and southern hemispheres as measured from Dynamics Explorer-2, Ann. Geophys., Ser. A, 5, 363, 1987.

Todd, H., S. W. H. Cowley, A. Etemadi, B. J. I. Bromage, M. Lockwood, D. M. Willis, and H. Luhr, Response time of the high-latitude ionosphere to sudden changes in the north-south component of the IMF, Planet. Space Sci., $36,1415,1988$.

Vickrey, J. F., R. R. Vondrak, and S. J. Matthews, Energy deposition by precipitating particles and Joule dissipation in the auroral ionosphere, J. Geophys. Res., 87, 5184, 1982 .

Winningham, J. D., et al., The UARS particle environment mouitor, J. Geophys. Res., 98, 10,649, 1993.

B. A. Emery, G. Lu, A. D. Richmond, and R. G. Roble, High Altitude Observatory, National Center for Atmospheric Research, P.O. Box 3000, Boulder, CO 80307-3000. (e-mail: ganglu@ncar.ucar.edu)

(Received November 17, 1994; revised January 30, 1995; accepted March 1, 1995.) 